\title{
Bank Credit And Business Networks
}

\section{Citation}

Khwaja, Asim ljaz, Atif Mian, and Abid Qamar. 2011. Bank Credit And Business Networks. HKS Faculty Research Working Paper Series RWP11-017, John F. Kennedy School of Government, Harvard University

\section{Published Version}

http://web.hks.harvard.edu/publications/workingpapers/citation.aspx?Publd=7695

\section{Permanent link}

http://nrs.harvard.edu/urn-3:HUL.InstRepos:4876870

\section{Terms of Use}

This article was downloaded from Harvard University's DASH repository, and is made available under the terms and conditions applicable to Other Posted Material, as set forth at http:// nrs.harvard.edu/urn-3:HUL.InstRepos:dash.current.terms-of-use\#LAA

\section{Share Your Story}

The Harvard community has made this article openly available.

Please share how this access benefits you. Submit a story.

Accessibility 


\section{Bank Credit And Business Networks}

\section{Faculty Research Working Paper Series}

\section{Asim ljaz Khwaja}

Harvard Kennedy School and NBER

\section{Atif Mian}

U.C. Berkeley and NBER

\section{Abid Qamar}

State Bank of Pakistan (SBP)

\section{March 2011 \\ RWP11-017}

The views expressed in the HKS Faculty Research Working Paper Series are those of the author(s) and do not necessarily reflect those of the John F. Kennedy School of Government or of Harvard University. Faculty Research Working Papers have not undergone formal review and approval. Such papers are included in this series to elicit feedback and to encourage debate on important public policy challenges. Copyright belongs to the author(s). Papers may be downloaded for personal use only. 


\title{
Bank Credit And Business Networks
}

\author{
ASIM IJAZ KHWAJA, ATIF MIAN and ABID QAMAR*
}

Feb 2011

\begin{abstract}
We construct the topology of business networks across the population of firms in an emerging economy, Pakistan, and estimate the value that membership in large yet diffuse networks brings in terms of access to bank credit and improving financial viability. We link two firms if they have a common director. The resulting topology includes a "giant network" that is order of magnitudes larger than the second largest network. While it displays "small world" properties and comprises 5 percent of all firms, it accesses two-thirds of all bank credit. We estimate the value of joining this giant network by exploiting "incidental" entry and exit of firms over time. Membership increases total external financing by 16.6 percent, reduces the propensity to enter financial distress by 9.5 percent, and better insures firms against industry and location shocks. Firms that join improve financial access by borrowing more from new lenders, particularly those already lending to their (new) giant-network neighbors. Network benefits also depend critically on where a firm connects to in the network and on the firm's pre-existing strength.
\end{abstract}

Keywords: Business Networks, Financial Development, Network Analysis

JEL: L14, O16, D85, D02

${ }^{*}$ Harvard University, Kennedy School of Government and NBER; U.C. Berkeley and NBER; and State Bank of Pakistan (SBP) respectively. E-mails: akhwaja@ksg.harvard.edu, atif@haas.berkeley.edu and abid.qamar@sbp.gov.pk. We thank seminar participants at Harvard University, Hitotsubashi University, the World Bank, and NBER Corporate Finance and Entrepreneurship Meetings for helpful comments and suggestions. The superb research assistance of Nathan Blecharc, Alexandra Cirone, Benjamin Feigenberg, Magali Junowicz, and Sean Lewis-Faupel is greatly appreciated. Special thanks to the Central Bank of Pakistan for answering numerous questions and for help in assembling the data set. However, the results in this paper do not in any way necessarily represent those of the Central Bank of Pakistan. All errors are our own. 
We live in a remarkably networked global economy. Whether through social relations or business ties, network links are thought to generate significant value. Several papers emphasize the importance of networks as conduits of information and enforcement, with networks adding value by facilitating the transaction of services, such as financial intermediation or employment/customer access, that rely on the quality of information and contract enforcement ${ }^{1}$. While their role and value may change as markets develop, networks remain salient even in developed nations.

Figure I graphs the network topology in the population of large/public firms in two developed (the United States and the United Kingdom) and two emerging (India and Pakistan) economies. Firms are linked if they have a director in common and drawing connections iteratively allows one to construct a network topology. Despite large institutional and economic differences, not only do networks appear equally salient across countries but the network structure appears strikingly similar. ${ }^{2}$ In particular, each country has one large network (henceforth referred to as the "giant network") which is orders of magnitude larger than the next largest network.

The existence of such a large network is in fact a common occurrence both in network theory (referred to as the "giant component/cluster") and in a large literature that examines real-world networks (see Albert and Barabasi 2002 for a review). ${ }^{3}$ The giant networks in Figure I have a diffuse and robust structure that displays "small world" properties (small distance between nodes with relatively high local inter-connectedness), have a low degree of "centralization" and encompass around half of the sample firms. Moreover, the network characteristics suggest that such giant networks are the result of a decentralized process of local link formations rather than the outcome of any central coordination.

This paper estimates the value in terms of bank credit that a firm obtains by joining such a business

\footnotetext{
${ }^{1}$ For example, Banerjee and Munshi, 2004; Fisman and Khanna, 2004; Leff 1976, 1979; McMillan and Woodruff, 1999; Mobius and Szeidl, 2007; Uzzi, 1999; and Cohen et al 2008.

${ }^{2}$ These countries were picked based on data availability. We used three different data sources - Boardex, OneSource and Pakistan's central bank. The former two sources typially provide information only on publicly listed and/or larger unlisted companies. The US and UK had more readily available/comprehensive data (Canada, the next most listed country in the Boardex database after the U.K., had less than a fifth as many firms listed), and we choose India for regional comparison with Pakistan. We should note that the seemingly "denser" apperance of the giant networks in the US and India in Figure I is a function of the larger firm sample size for those countries and that all four giant networks show similar network characteristics. We restrict the main analysis in this paper to just one emerging country (Pakistan) since we were able to obtain a much more comprehenesive firm database which includes both firm directors/owners and firm financial access for all firms borrowing from any formal lending institution in the economy. This allows us to take better advantage of our empirical methodology of focusing on changes in network membership and "incidental" entry/exit.

${ }^{3}$ Erdos and Renvi (1959 and 1960) show that even random matching of nodes in a system is likely to produce a giant cluster. However, most real networks - including the ones shown in Figure I - are unlikely to have been generated by a random matching process since they display a much higher clustering coefficient (a measure of inter-connectedness) than a randomly-connected graph would and the degree (number of links) distribution of the nodes follows a power law rather than a Poisson distribution that one would expect under random matching.
} 
giant network. Our focus on the giant network has two main advantages. First, as pointed above, the giant network structure is common acrosss the world. Second, as explained below, we provide a new methodology based on "incidental entrants" to estimate a plausibly unbiased estimate of the impact of network membership. Such a methodology requires the entry and exit of small networks of firms into a larger network.

There are a variety of empirical challenges in trying to estimate the impact of business networks on firm outcomes. First, one needs data on the entire population of agents in the economy in order to construct an accurate topology of connections. In the case of business networks, most data sets that provide board/owner information cover only publicly listed or large companies. Since smaller private firms form the overwhelming majority of business enterprises, any network analysis limited to large or public firms may miss important links. Second, networks are the cumulative result of strategic choices that agents make when forming relationships. Therefore, one must be careful in separating the causal effect of networks from possibly spurious selection effects (i.e., business networks may select firms to join based on unobserved firm characteristics which affect future firm performance). Finally, network theory highlights that network benefits depend critically on where in the network one is connected. One therefore needs to be able to examine such heterogeneity by utilizing credible measures of network strength, such as the "linkage power" of a node, in order to better understand the process through which networks bring value.

We address these challenges using novel firm level data that covers the universe of more than 100,000 firms in Pakistan over a four year period and by exploiting a methodology that can be replicated in other settings, for both other economies and other sectors or outcomes. The data comes from the central bank of Pakistan, which supervises the banking sector, and contains information on each firm's lending relationships, credit history, and importantly, identifying information for the members of its board of directors. We construct interlocked, board-firm networks as in Figure I (but for a more comprehensive sample of firms) and measure the strength of network connections and nodes using concepts from graph theory. The giant-network structure remains similar to that in Figure I (see Appendix Figure I). Importantly, we can accurately track how this network topology changes over time. This allows us to estimate the value that entry into or exit from the giant network brings in terms of credit access and financial viability. We follow changes in network membership at six-monthly intervals and look for differences in credit access for firms that enter or exit the giant network. Our 
focus on time-series variation in network membership for a given firm absorbs any unobserved timeinvariant firm attribute that jointly determines network membership and access to credit.

However, a remaining concern is that entry and exit from the giant network may be driven by timevarying changes in firm quality. For example, firms with better anticipated growth prospects may be more likely to join the network. If that were the case, an increase in access to credit after entering the network may be driven by unobserved improvements in firm quality and not direct benefits of the network, per se.

We address this issue by introducing a methodology for estimating network benefits particularly suited for cases where there is a clearly defined giant network. The idea is to focus on the effect of (giant-)network membership for incidental entrants/exitors and to compare this with the effect for direct entrants/exitors. Incidental entrants are firms that enter the giant network not because of any changes in their board of directors, but because of changes in the board of directors of a neighboring firm that they were already linked to. For example, consider Firms A and B with three directors each and only one director, Director 1, in common. Both firms are initially not in the giant network. Now suppose that Firm A enters the giant network because one of its existing directors (other than Director 1) is invited to be on the board of a giant-network firm. Firm A has entered "directly" into the network. Firm B, however, enters the network "incidentally." It joins the network not because one of its directors was selected to join a giant-network firm but only because it happened to be connected to a firm (A) that joined the network. Incidental exitors are defined analogously.

To the extent that incidental entry/exit occurs due to factors that are unrelated to a firm's (future) performance, the impact on incidentals provides the equivalent of an unbiased instrumental variable estimate of the impact of network membership. However, one could still argue that focusing on incidentals may not eliminate the time varying selection concern. While it is typically hard to empirically defend an instrument, an additional advantage of our methodology is that a comparison of the effect between direct entrants/exitors and incidentals (after matching on firm attributes) provides an estimate of the sign and severity of the selection effect. Thus, if one finds, as in our case, that the effect of network entry/exit is similar for both direct and incidental entrants/exitors, this provides additional evidence that the time-varying selection is not a serious concern. In other words, on the margin (i.e. for firms that enter or exit the giant network during our sample period) even direct entry/exit seems to be driven by time-varying social factors and not by time-varying firm performance factors that affect 
future firm performance.

We find that the impact of giant-network membership is large. It leads to a 16.6 percent increase in bank credit and a 9.5 percent decline in the propensity to enter financial distress. The increase in bank credit is due to both an increase in average borrowing and the formation of new banking relationships. New banking relationships reflect the importance of the "referral channel": They are more likely to be formed with banks that already have a lending relationship with one of the immediate giant-network neighbors of the newly networked firm.

The benefits of giant -etwork membership also depend on where in the network one is connected. In terms of access to bank credit, firms benefit more from entry when they connect to more powerful parts of the giant network. However, gains in credit access are tempered if a firm was already powerful (that is, for bank credit, entry into the giant network is a substitute for a firm's pre-existing power and has diminishing returns). We measure power of a connecting node in a number of different ways, including number of direct links to other firms/directors within the network, the strength of these neighbor firms, and a measure analogous to "Google PageRank."

Overall, our results shed useful light on the likely channels through which network memberships gives acces to credit. In particular, they favor theories where network benefits depend on credible maintenance of links, rather than theories where network membership acts as a signalling device. We discuss this in more detail in conclusion.

The role of business networks in improving firm performance and access to bank credit has been emphasized in the context of early American history by scholars such as Lamoreaux, 1986. While there has been considerable work in network theory (see Jackson, 2004), empirical work lags behind. ${ }^{4}$ Our paper provides three key contributions in this regard. First, it uses the entire population of firms in an economy, rather than any specific subset, to construct networks. We can thus be reasonably confident that we are not missing important network connections in our analysis.

Second, earlier work mostly focuses on estimating cross-sectional differences between networked and non-networked firms, making it difficult to control for unobserved, firm-specific attributes that determine both network membership and the outcome of interest. Our paper not only uses time-

\footnotetext{
${ }^{4}$ Some notable exceptions include: Grief (1993), who examines the role that networks of traders played in overcoming barriers to international trade; Feenstra et al. (1999), who find that networks matter for explaining differences in quality and variety of exports across South Korea, Taiwan, and Japan; Hoshi, Kashyap, and Scharfstein (1991), who show the importance of networked firms in getting access to credit in Japan; Hochberg et al. (2007), who show that betternetworked VC funds are correlated with better performance; and Khanna (2000), who in a series of papers also examines the structure and importance of business groups.
} 
series changes in network membership for a given firm, thus enabling the use of firm fixed effects to address unobserved, firm-specific factors that may influence network membership, but can also address additional concerns of time-varying firm-level unobservables. It does so both through non parametric controls and the use of incidental entrants as potential instruments and a means of identifying any (remaining) selection effects.

A third contribution of our paper is that we do not treat the network as a homogenous entity. As frequently noted by sociologists (e.g., Burt 1992, Granovetter 1973) and economic theorists (e.g., Jackson and Wolinsky, 1996; Johnson and Gilles, 2000; Belleflamme and Bloch, 2002; Calvo-Armengol and Jackson, 2001; Kranton and Minehart, 2001), not all nodes and links within a network are created equal. Hence, the value of a network to its members is not uniformly distributed but depends on where and with whom a firm is connected. Moreover, firms of different initial power may benefit differentially from the network. While previous studies have rarely examined such heterogeneity of network effects, ${ }^{5}$ we are able to make headway due to our ability to observe both pre- and post-entry variation in firm power attributes.

\section{Defining Business Networks}

\section{A. Data $\&$ Context}

We use two data sets in this paper, both from the central bank of Pakistan. The first data has information on the board of directors of all borrowing firms in the economy from 1999 to 2003 at six-month intervals. The second has detailed loan level information on these firms' borrowing over the same period at a quarterly frequency. We describe each of these below. However, before doing so, we should note that both the industrial and banking sector in Pakistan is fairly liberal and representative of emerging markets. There are few restrictions on firm entry and exit and while there are large state companies in several sectors, there is substantial foreign/multinational and domestic private sector presence. While firms do face a variety of market obstacles and inefficiencies, these are not significantly different from those in other emerging economies. Private, foreign, and government banks constitute roughly equal shares of domestic lending. Financial reforms in the early 1990s brought uniform prudential regulations in-line with international banking practices (Basel Accord),

\footnotetext{
${ }^{5}$ A recent review article by Rauch and Hamilton (2001) makes the same point.
} 
and autonomy was granted to the central bank for regulation. While some political efforts have been made to bring banking in accordance with Islamic shariah laws, it has not had any significant functional impact on banking. For all practical purposes, banking follows global norms with deposit and lending rates determined by the market. While we are not comfortable going so far as to claim our results (on the value generated by network membership) readily generalize to other settings, it is nevertheless reassuring that Pakistan's industrial/banking sector and firm network topology does not appear atypical of emerging economies.

\section{(i) Board of Directors Information}

The central bank of Pakistan maintains a list of the board of directors of all firms borrowing from any bank in the country. We have this data from 1999 to 2003 at a semiannual frequency for well over

100,000 firms that represent the universe of all borrowing firms in the economy. The data records the full name, father's name, national identification card (NIC) number, and percentage of equity held for each director of a firm at a given point in time.

Since we ultimately want to link two firms together if they have a director in common, it is important to uniquely identify individuals in our board of directors data set. The NIC number issued by the government serves this purpose, as it is unique to every individual. However, reporting of the NIC number is not mandatory, and this information is missing or incomplete around 16 percent of the time. When we do not have NIC information, we identify and track individuals over time and across firms by matching an individual's full name and their father's full name (or husband in the case of married women). We deliberately utilize a stringent criteria for matching director names so as not to incorrectly connect two firms. Our matching criteria gives us a total of 261,069 unique directors for 139,526 firms in our sample. In our final sample, we drop very small firms with less than Rs.500,000 (about US $\$ 8,500$ ) of borrowing at the beginning of our sample period since these firms have very noisy loan amounts, frequently going from positive to zero amounts. Exclusion of these firms leaves us with a total sample of 105,917 firms. The results are qualitatively similar even if these firms are included. 


\section{(ii) Firm Borrowing Information}

We also have quarterly information on a firm's loan from any bank it borrows from over a sevenyear period from 1996 to 2003. The data is at the level of a loan (i.e., firm-bank pair) and traces the history of firm borrowing with information on the amount of the loan (principal and interest), outstanding balance, and amount in default. The outstanding loan amount is further broken down into different categories, such as term loans, working capital, etc. The default amount starts appearing in our data set as soon as a loan payment is overdue by thirty days or more. Although the original data is at the level of the loan, for most of our analysis, we aggregate loans to a given firm across its lenders at a given point in time. Since the director data is available at six month frequencies from 1999 to 2003 , we only use the loan data that corresponds to these time periods. ${ }^{6}$

In terms of data quality, our personal examination of the collection and compilation procedures, as well as consistency checks on the data, suggest that it is of very good quality. Our data was part of an effort by the central bank to set up a reliable information sharing resource that all banks could access. A credible signal of data quality is that all banks refer to this information on a daily basis to verify the credit history of prospective borrowers. Our checks with one of the largest and most profitable private banks in Pakistan revealed that they use the information about prospective borrowers explicitly in their internal credit scoring models. We also ran several internal consistency tests on the data, such as aggregation checks, and found it to be of high quality. As a random check, we also showed the data from a particular branch of a bank to that branch's loan officer who confirmed the authenticity of the data related to his portfolio.

\section{B. Network Description}

We use information on firm directors to construct networks and link two firms if they share a common director (i.e., have interlocked boards). ${ }^{7}$ Figure II illustrates the hypothetical construction of a network through this process. There are eight firms in the example (A through $\mathrm{H}$ ), and a total of fifteen directors sitting on the board of these firms (numbered 1 through 15).

Interlocked board linkages produce two distinct networks and two firms ( $\mathrm{G}$ and $\mathrm{H}$ ) that are not connected to anyone else. The largest network consists of Firms A through D, where Firms A, B,

\footnotetext{
${ }^{6}$ We use 1996-1998 data to construct lagged measures of loan growth and change in default.

${ }^{7}$ Our use of interlocked directorates to define networks has a long tradition among social scientists (e.g., Mintz and Schwartz, 1985; Stokman et al., 1985; Scott, 1987).
} 
and $\mathrm{C}$ are linked to each other directly and Firm D is linked to Firms A and B indirectly through its direct link with C. Thus, firms in the same network may be linked to each other through long chains of indirect links.

A second feature to take away from Figure II is that firms within a network vary by how "important" they are in the network. For example, Firm C is important in the network because it has the most number of firms directly connected to it (three firms). Similarly, links between firms can vary in their "strength." For example, Firms E and F are connected to each other through three directors (the number on the link represents the number of directors generating the link). We shall exploit such heterogeneity in the strength of network nodes and links to test if the strength of connections is also important in determining the advantage that networks bring to connecting firms.

We apply the principle outlined in Figure II to construct networks at a point in time. Doing so gives us eight snapshots of the structure of business networks in Pakistan - once for every six months from 1999 till 2003. As a consequence, we can not only observe how networks evolve over time but also isolate the entry and exit of individual firms from specific networks. Almost two-thirds $(66,140)$ of firms are never linked to any other firm at any point in time. The remaining third of firms belong to multi-firm networks in at least some of the periods (Table I, Panel A). ${ }^{8}$ The size (that is, the number of firms in the network) distribution of multi-firm networks reveals a striking pattern in every period. Network size varies in any given period from 2 to 85, followed by a single "giant network" of about three thousand firms. ${ }^{9}$

The size of the giant network, as well as the identity of its firms, changes over time due to the addition or removal of directors from firms or because of firm creation or dissolution. There are 2,838 firms that are always part of the giant network and 2,457 firms that belong to the giant network for some, but not all, of the periods. Table I, Panel A shows the distribution of firms by network size and some summary statistics. While about 5 percent of firms $(5,295)$ belong to the giant network at some point in time, the share of these firms in total bank credit is 65 percent, signifying the relative economic importance of the giant network. Out of the remaining firms, precisely 34,482 belong to networks of size 2 through 85 at some point during our sample period. These firms collectively borrow about 21 percent of total bank credit, with the remaining 15 percent going to non-networked firms.

\footnotetext{
${ }^{8}$ See Appendix Figure 1 for all the network structures in the economy.

${ }^{9}$ The giant-network size varies somewhat in each time period but remains within two and a half to three thousand firms. This results in over five thousand distinct firms that are in the giant network at some point in the four-year period.
} 
Figure III (Panel A) illustrates the giant network by taking a union of the giant networks over the eight six-month periods. Firms that always remain inside the giant network are represented by black dots, while firms that enter and/or exit the giant network are represented by red dots. Firms are linked if they share a common director at some point in time. The large number of firms and high density of links in the giant network make it difficult to see the intra-network details in the top-panel of Figure III. We therefore zoom into a couple of different areas of the giant network to provide more clarity as to what the network structure looks like. Panel B zooms into an area closer to the "core" of the giant network. ${ }^{10}$ While each dot represents a firm, the number inside the dot represents the number of firms that the firm is connected to. Panel $\mathrm{C}$ zooms in to a more peripheral area of the giant network where firms have a lot fewer connections to other firms.

Figure III highlights a couple of important giant network characteristics. First, the network is quite strongly interconnected, with no single "hub" firm (or a small subset of such firms) holding the entire network together. The number of links per firm is relatively small even in the core of the giant network (Panel B). Moreover, robustness tests shows that even after the removal of firms that have the most number of links, the giant network retains its overall structure (see the appendix for more details on this and other related checks regarding the robustness of giant-network structure). A second feature reflected in the figures is that there is heterogeneity in the strength with which a firm is connected to the giant network. Some firms hang on to the giant network with one or two connections, while others are very strongly interconnected with multiple links. Similarly, some firms are connected to more "powerful" firms within the giant network than others.

A number of network statistics suggest that our giant network displays "small-world" properties (Jackson and B. Rogers, 2005; Watts and Strogatz, 1998). The average distance (number of links) between any two firms is 6.5 links, surprisingly close to the canonical "six degrees of separation" example. The maximum distance (diameter) between any two firms in the network is twenty-three, which is quite low given the total size of the network. ${ }^{11}$ The network displays a reasonably high degree of clustering, with a clustering coefficient of 0.65. A maximum clustering coefficient of one reflects that each node is fully connected to every two nodes around it. A network has a clustering coefficient of zero

\footnotetext{
${ }^{10}$ The graphs were plotted using Cytoscape. The software computes the "centrality" of every node before deciding whether to place a node in the center or at the periphery. For example, an important node with many connections to other firms within the network is likely to be placed closer to the core of the network structure. On the other hand, a node with a few connections is more likely to sit at the periphery of the network structure.

${ }^{11}$ For example, in a linear network, the diameter would have been one less than the total number of firms in the network (over five thousand in our case).
} 
if all nodes are connected through a chain of single links to one another. ${ }^{12}$ Finally, the giant network has a very low centralization measure of 0.02 . A network obtains a centralization coefficient of 1 if each node is connected to the other through one central hub (a "hub-and-spoke" network). The network statistics, coupled with the visual evidence shown in Figure III, suggest that the giant network is a consequence of decentralized linking across firms rather than a set of coordinated centralized actions.

Panel B in Table I provides summary statistics on various measures of a firm's "network power." We present summary statistics of power measures only for firms that enter or exit the giant network during our sample period. The reason for this restriction is that we identify the effect of giant-network membership from time-series variation provided by these firms. We separately provide power measures for when a firm is in the giant network and when it is out.

The simplest power measure is the number of other firms to which a firm is directly connected. On average, a firm in the giant network is directly connected to 5.38 other firms. These direct connections drop to 3.08 when a networked firm is out of the giant network. Similarly, the number of directors that a firm is linked to (through neighboring firms) drops from 34.7 to 9.49. The number of neighbors' lenders is defined as the banks (not counting the firm's own lenders) that the firm's neighbors are borrowing from. This measure changes from 10.5 to 5 for firms in and out of the giant network.

Finally, we also construct a measure of the firm's strength in the network using the algorithm utilized by Google to rank the relative strength of web pages. This "Google PageRank" captures the importance of a firm iteratively in terms of how many firms it is linked to and how important those firms are in terms of how many firms they are linked to, and so on ${ }^{13}$. Given its theoretical foundation

\footnotetext{
${ }^{12}$ The giant network is quite "efficient" in achieving the high clustering coefficient. For example, to achieve a coefficient of one where all firms are connected to each other requires $N *(N-1) / 2$ links (about 14 million). Yet the giant network achieves a high clustering coefficient with only about eighty thousand links, around half a percent of that. Moreover, the high clustering coefficient suggests that the network is unlikley to have been created through a process of random linking of nodes. In a randomly connected graph, the clustering coefficient, is equal to $\mathrm{k} / \mathrm{N}$ where $\mathrm{k}$ is the average degree (links) of a node and $\mathrm{N}$ is the total number of nodes. If our network was a result of random matching, the clustering coefficient should have been less than 0.01. Similarly the degree distribution of a randomly connected graph is a Poisson distribution with a peak at $\mathrm{P}(\mathrm{k})$, where $\mathrm{k}$ is the average degree of the network. However, our network, like most real-world networks, shows a power-law degree distribution.

${ }^{13}$ In particular, the google page rank computes the relative probability than an individual randomly clicking on web page links will arrive at any particular web address. We modify this measure to our case (of undirected links) but the interpretation is similar (for ease of comparison in the regressions we eventually normalize the variable to a mean and std dev of 1). A borrower's page rank therefore captures the likelihood that we would reach this borrower if we randomly followed (inter-locked-board) linkages i.e. it intuitively captures how "connected" a borrower is. More specifically, this measure iteratively constructs the link "importance" of a borrower. Unlike simpler measures, such as the number of links a borrower has, the page rank algorithm is preferred since it goes beyond simply counting a borrower's direct links but weighs these links in turn by the (link-)importance of the borrowers the borrower is connected to which in turn is defined recursively. Thus two borrowers with the same number of direct links can get very different page ranks if one is connected to borrowers that themselves are connected to more borrowers, who in turn are connected to more and so on.
} 
and practical success, Google PageRank is our preferred summary statistic for measuring network power.

\section{Empirical Methodology}

\section{A. Basic Setup}

The dominance of the giant network vis-à-vis other smaller networks is illustrated in Appendix Figure I, which graphically displays the network structures for all borrowing firms in the economy. Moreover, as already emphasized in the introduction, both theoretically and empirically, the presence of giant networks seems to be a common phenomenon. Given the significant, selection-related challenges in identifying the value of network membership, we develop a methodology that uses giant networks to do so. While we apply this to business networks in Pakistan and to a specific set of outcomes (financial access), the methodology can readily be extended to networks in other sectors and economies, provided one has comprehensive data that permit an examination of the evolution of these structures over time and that relate to outcomes of interest.

The challenge in identifying the causal effect of entry into the giant network is that firms that enter the giant network might be systematically different from firms that do not. Thus, any observed difference between networked and non-networked firms may be spuriously driven by unobserved "selection" factors rather than by the direct effect of network membership.

Consider a giant network with $n$ nodes, where each node represents a firm. Two nodes are linked if they have a director in common, and all nodes in the network are ultimately connected to each other through such links. We denote individual nodes with $N_{m}$ where $m$ varies from 1 to $n$. There is a burgeoning literature on how networks form, survive, and evolve over time (see Jackson, 2004, for a review). However, a full model of network formation is beyond the scope of our paper. We therefore take the $n$-node network as given and estimate the impact of network membership on the marginal firm joining the network.

Suppose firm $i$ attempts to join the network every period $t$ by trying to establish a link with an existing network node. Such a link can be established if one of the board members of firm $i$ joins the board of a networked firm. Alternatively the link can be established if a director of an already networked firm joins firm i's board. 
In order to estimate the direct benefits of network membership, a key question is: What determines which firm $i$ enters the network, and when? Network entry is determined by a selection equation that specifies whether and when a firm enters the giant network. Let $h_{i t}$ denote the hazard rate that firm $i$ enters the network at time $t$, conditional on not having entered already. Without much loss of generality, we assume that $h_{i t}$ depends on expected firm productivity, $\pi_{i t}$, and "incidental factors," $x_{i t}$, that are orthogonal to firm productivity. An example of incidental factors is social ties that do not influence firm performance but help a firm gain entry. It is plausible that firms with higher expected productivity and "better" incidental factors are more likely to enter the network:

$$
h_{i t}=\Phi\left(\pi_{i t}, x_{i t}, \eta_{i t}\right)
$$

where $\Phi$ is a cumulative distribution function and $\eta_{i t}$ is an i.i.d random component. For simplicity, we assume separability of these factors.

$\pi_{i t}$ evolves through a stochastic process such that each firm starts with a firm specific productivity $\pi_{i 0}$ in period 0 , and then evolves according to $\pi_{i t}=\pi_{i, t-1}+\nu_{i t} . \nu_{i t}$ is a firm specific productivity shock every period and may not be independent across firms or over time.

Let $Y_{i t}$ reflect a measure of firm performance in the credit market that we can use to calculate the benefits of network membership. Our paper uses two such measures: (i) access to external finance (which is also closely related to firm sales and inventory); and (ii) propensity to enter financial distress.

In order to illustrate the difficulty in identifying the benefits of network membership, suppose we try and do so by comparing the performance of networked and non-networked firms through the equation:

$$
Y_{i t}=\alpha+\beta_{1} E N T R Y_{i t}+\varepsilon_{i t}
$$

where $E N T R Y_{i t}$ is an indicator variable for whether firm $i$ is part of the giant network in period $t$. The key concern regarding identification of $\beta_{1}$ is that outcomes $Y_{i t}$ are likely to depend not only on network membership, $E N T R Y_{i t}$, but also firm productivity, $\pi_{i t}$. Since $E N T R Y_{i t}$ itself is a function of $\pi_{i t}$ through Equation (1), we have the usual simultaneity/omitted variable problem. 


\section{B. Identification}

We address the possibly spurious effect of $\pi_{i t}$ on $\widehat{\beta}_{1}$ using two types of approaches: non-parametric controls and an instrumental variable strategy that uses incidental entry/exit. 


\section{Non-parametric controls}

The first approach uses non-parametric controls to absorb firm specific factors that might determine network entry and firms' credit market performance simultaneously. A key component of $\pi_{i t}$ that influences entry into the network is the initial productivity level of a firm, $\pi_{i 0}$. While we do not observe this parameter, we can completely absorb it from the estimating equation by including firm fixed effects $\alpha_{i}$ in Equation (1). Firm fixed effects account for any level differences in productivity across firms. ${ }^{14}$

However, this still leaves open the concern that firms are more likely to enter the network at certain points in time when, for example, the industry they belong to happens to get a series of positive shocks. We make another non-parametric adjustment to account for such time-varying productivity factors by including in Equation (2) all interactions of firm-type fixed effects with time fixed effects $\left(\alpha_{k t}\right)$, in addition to the firm-fixed effects. Firm type, $k$, in our regressions includes separate classifications for a firm's location, size decile, and industry.

While this addresses a variety of time-varying shocks, $\beta_{1}$ may nevertheless be influenced by other time-varying specific shocks, $\nu_{i t}$, that are idiosyncratic to a particular firm. For example, a given firm may be more likely to join the giant network after it receives a series of positive permanent shocks ,$\left\{\nu_{i t}\right\}$, that are unrelated to its sector, location, or size decile. While we do not observe such firmspecific shocks, if these shocks were influential, conditional on entry in $t$, a firm should have a higher growth trajectory for $Y$ prior to $t$.

Thus, one can test whether $\beta_{1}$ is driven by time-varying shocks to firm productivity by including lagged growth rate of $Y_{i t}$ and checking if $\beta_{1}$ drops substantially. The combination of non-parametric and lagged growth rate controls gives us the following estimation equation:

$$
Y_{i t}=\alpha_{i}+\alpha_{k t}+\alpha_{t}+\gamma * \Delta Y_{i, t-1}+\beta_{1} E N T R Y_{i t}+\varepsilon_{i t}
$$

where $\alpha_{i}$ are firm fixed effects, $\alpha_{k t}$ is firm-type $(k)$ interacted with date fixed effects, and $\triangle Y_{i, t-1}=$ $Y_{i, t-1}-Y_{i, t-2} \cdot{ }^{15}$

\footnotetext{
${ }^{14}$ Panel A in Table I shows that firms that are part of the giant network are on average much larger and have much lower default rates than firms outside the network. Such fixed time-invariant differences between networked and non-networked firms are absorbed away by the firm fixed effects.

${ }^{15}$ Since Equation (3) is a fixed effects regression, we need to be careful in including lagged dependent variables. Including levels of lagged dependent variables would be problematic since the lagged term would be correlated with the fixed effect. While one could correct for this using Arellano-Bond style corrections, our specification uses lagged growth of the dependent variable. Since this lagged term is in changes (i.e. $Y_{i, t-1}-Y_{i, t-2}$ ), the immediate concern that it is
} 


\section{Incidental Entry/Exit}

Our second approach to addressing potentially endogenous entry into the giant network is based on exploiting incidental entrants/exitors. We use this both as a potential instrumental variable and as a way of providing a sense of the biases that may arise from time-varying selection effects.

A limitation of Equation (3) is that, while it is able to address firm-type time trends and outcome pre-trends, it is still possible that an unobserved, firm-specific, and time-varying factor influences both network membership and the outcomes of interest. In the terminology of the hazard function (1), ideally we would like to instrument entry with an incidental parameter $x_{i t}$.

We propose such an instrument based on the "incidental" entry of some firms into the giant network. There are two distinct ways in which a firm can gain entry into the giant network: direct and incidental. Figure IV, based on our actual data, illustrates the difference between the two.

The example in Panel A shows three firms before and after they enter the giant network. The firms are connected because they each have a director in common, but there is no director common to all three. Two firms (\#100 and \#101, colored as white) join the giant network directly because their common director is invited to sit on the board of an existing giant-network firm. The third firm (\#102), colored in yellow, enters the giant network incidentally as none of its directors are invited to sit on the board of an existing giant-network firm.

Panel B depicts another example of incidental and direct entry into the giant network where the nature of the direct entry is slightly different. Instead of the direct entrant's director being invited to sit on a giant-network firm's board, in this case, the direct entrant receives a new director who also sits on a giant-network firm's board. As in the previous example, the three firms have a common director and are thus linked to each other. One of the firms (\#106) adds a new director who already happens to sit on the board of one of the networked firms. Thus, firm \#106 enters the giant network directly. Firms \#104 and \#105 (colored in yellow) join the giant network incidentally since none of their directors are invited to sit on a giant-network firm, nor do they add a new (giant-network) director. ${ }^{16}$

correlated with the fixed effect is not present as it is differenced out. Moreover, we believe this is a more appropriate correction (i.e., we are concerned about controlling for a firm's past growth trajectory).

${ }^{16}$ While one could separate incidental entrants based on which of the two types of direct entry their connecting firm experiences (Panel A versus Panel B), we do not do so. This is both because of sample size limitations and because there is no clear reason to think this would improve identification as it is not clear whether one form of direct entry faces a stronger selection problem than the other. 
We analogously define incidental exits; that is, firms that exit the giant network indirectly because one of the firms they are connected to experiences either a removal of a giant-network firm director from its board or because one of its directors no longer sits on the board of another giant-network firm.

We use incidental entry/exit as an instrument for entry/exit. Incidental entrants/exitors are reasonable candidates for instruments because these firms join/leave the giant network without any direct change in the composition of their own board. Similarly, none of their directors takes a seat on the board of a giant-network firm. Therefore, incidental firms are not joining or leaving the giant network through an active decision that involves their board. As such, it is likely that incidental entry/exit is orthogonal to changes in firm level fundamentals and hence to a firm's future trajectory.

Furthermore, there is empirical evidence to support this. If incidental entrants enter the giant network by chance, there should not be any significant difference between incidental entrants prior to giant-network entry and other similar firms that (by chance) do not enter the giant network. In order to test this condition, it is important to understand what kind of firms have the potential to become incidental entrants.

A firm can enter the giant network incidentally only if it is connected to some other firms, one of which enters the giant network directly. Thus, standalone, non-networked firms can never become incidental entrants. More importantly, the probability of incidental entry likely monotonically increases with the size of the network that a firm belongs to before entry into the giant network. Therefore, the natural comparison cohort of incidental entrants belonging to a network of size $k$ at time $t-1$ is the set of non-entrant firms at time $t-1$ that also belong to a network of size $k$ but never enter the giant network.

Figure V compares firms in networks of various sizes. Panel A illustrates sample networks of various sizes $k$ that end up entering the giant network at some point during our sample period. While a few of the firms in each network enter directly, the remaining firms enter incidentally. Figure $\mathrm{V}(\mathrm{B})$ illustrates a comparison sample of firms. These firms also belong to various networks of size $k$, but they never enter the giant network. As an example, consider the two networks with $k=6$ in Figures $\mathrm{V}(\mathrm{A})$ and $\mathrm{V}(\mathrm{B})$, respectively. For the sake of argument, suppose that one of the firms in $\mathrm{V}(\mathrm{A})$ network enters directly, with the remaining entering incidentally. If incidental entry is truly driven by factors orthogonal to firm performance, then the five firms that happen to enter the giant network incidentally 
in Figure $\mathrm{V}(\mathrm{A})$ should be no different (prior to giant-network entry) than the six in the $k=6$ network in Figure V(B).

We check whether this is true in our data by using pre-entry network-size fixed effects and comparing outcomes for incidental firms, prior to giant-network entry, with their relevant cohort (of non-entering) firms. We check for differences on our two key performance metrics, growth in bank credit and changes in default status. The result shows that there is no difference between incidental firms and firms that do not enter the giant network in either of the two metrics. The difference in growth rate of bank credit between incidental entrants and non-entrants belonging to same-sized networks is less than 0.5 percent and insignificant (p-value of 0.84). Similarly, the difference in changes in default rate is less than 0.04 percent and insignificant (p-value of 0.89 ). These results lend support to our identification strategy. For example, if incidental entrants were improving prior to giant-network entry, they should have had relatively declining propensity to default compared to similarly networked firms that do not enter. As our results show, this is not the case.

In addition, one can ask whether incidental entrants' and exitors' performance (while they are out of the giant network) co-varies with that of the firms whose direct exit or entry caused the incidental change in giant-network membership. Were this the case and even if only a direct entrant/exitor was purposely selected to join the giant network, one may be concerned, for instance, that those firms who are incidentally joining the giant network would also show an improvement because of an underlying, pre-existing correlation between incidental and direct giant-network members. As an additional check, we find that, conditional on the firm attributes which we control for in our specifications, there is no significant correlation in either borrowing size or default rates between direct entrants and their incidental companions when both are out of the giant network.

Since incidental entrants and exitors are a strict subset of the firms that enter the giant network, the IV estimate is analogous to separately estimating the impact on incidental and direct entrants. We therefore augment the previous specification and estimate:

$$
Y_{i t}=\alpha_{i}+\alpha_{k t}+\alpha_{t}+\gamma * \triangle Y_{i, t-1}+\beta_{1} E N T R Y_{i t}+\beta_{2} E N T R Y_{i t} * \text { Direct }_{i}+\varepsilon_{i t}
$$

where Direct $_{i}$ indicates a firm which at some point directly enters/exits the giant network. $\beta_{1}$ is our coefficient of interest (the analogous IV estimate) since it isolates the impact of giant-network membership on the incidental entrants/exitors. 
Like in all IV estimates, $\beta_{1}$ in Equation (4) is, therefore, effectively a local average treatment effect (LATE) and does not estimate the overall average treatment effect (ATE) of entry into the giant network. Recall that the LATE estimator can differ from the average treatment effect if the subset of firms affected by the instrument are systematically different and if there is heterogeneity in the treatment effect (Imbens and Angrist, 1994). In our framework, firms affected by the instrument are the incidental entrants and exitors, and there are plausible reasons to believe that the treatment effect for these firms may be different than the treatment effect for direct entrants.

Incidental entrants enter the giant network indirectly and hence have a "weaker" connection with the giant network. If the effect of giant-network entry is smaller for firms that connect weakly, our LATE estimate will be smaller than the average treatment effect. Fortunately, an advantage of our data set is that we can directly measure the strength with which firms are connected to the giant network, as well as their pre-entry network strength (e.g., the Google PageRank measure explained earlier). Thus, we can directly test if such heterogeneity in treatment effect is present and control for it. $^{17}$

In addition, an advantage of our methodology is that a comparison of the effect between direct and incidental entrants/exitors (after matching on firm attributes) provides an estimate of the sign and severity of the selection effect as long as the potential selection effect is stronger for direct entrants/exitors relative to incidental entrants/exitors. In other words, if one finds, as we do, that the effect of network entry/exit is similar for both direct and incidental entrants/exitors (once we have taken treatment heterogeneity into account) this provides additional evidence that the time-varying selection concern is not serious: that is, even direct entry/exit seems to be driven by time-varying social factors unrelated to future financial borrowing/performance and not by time-varying firm performance factors that impact its future financial trajectory ${ }^{18}$.

\footnotetext{
${ }^{17}$ Ultimately, our startegy also implies that (even for the direct entrants) we may not be capturing the average treatment effect for the typical firm in the giant network. Since we identify our effect by utilizing firm fixed effects, we can only do so for firms that enter/exit the network over time. The estimated effect may be different from that for a firm that is so strongly connected that it never exits the giant network. While we are far more cautious in doing so (since it entails out-of-sample predictions), the treatment heterogenity estimates that we find could also be used to provide a sense of how large the network memebership effect is for the typical firm in the giant network. Since firms that never exit the giant network have larger connection power measures (and given our results in Table VI), this suggests that such average treatment effects are even larger than what we find for the entering/exiting firms.

${ }^{18} \mathrm{~A}$ reminder that this is a statement about the "treatment group" only, i.e. firms that enter or exit the sample during our sample period. The selection on firms that always remain in (or out) of the network is very strong, i.e. firm fixed effects -as we show later - change the coefficient of interest significantly.
} 


\section{Estimating Network Benefits}

We use two measures of firm performance in the credit market to estimate the impact of giantnetwork membership. The first is total borrowing from the banking sector. As explained earlier, the value provided by a network can increase both the supply and demand for bank credit for a firm. Our second measure of performance is financial viability, or the ability of a firm to prevent financial distress (defined as being late on loan payments for over thirty days). Any improvement in firm growth and profitability due to network access should make a firm more financially viable and hence less likely to enter financial distress.

Before presenting the regression estimates, Figure VI illustrates what happens to these two measures of firm performance as a firm enters the giant network during our sample period. Since the analysis is done in event-time, with time of entry defined as time zero, we take out economy wide aggregate effects and include firm fixed effects before plotting data over the event-time horizon.

Panel A shows a discrete jump in total bank credit of about 6 percent as a firm becomes a member of the giant network; it then gradually increases over time. The discrete jump at entry is statistically significant as well. Importantly, there is no statistically significant upward trend in bank credit prior to entry into the giant network, lending credibility that our regressions estimates are unlikely to be biased. Since our unit of time is six months, the figure plots what happens to firms up to two years before and after firm entry.

Panel B shows the corresponding graph for firm financial distress. While there is a general trend of declining default over time, the gradient becomes significantly steeper after a firm enters the giant network. Given the nature of the financial distress variable, any improvement in financial viability due to network entry will only show gradually as lower probability of financial distress. It is thus reasonable that, unlike bank credit, the probability of financial distress does not jump quickly after entry but rather starts to decline at a faster rate. While there is a significant gradient change after entry, the declining pre-entry trend in firm default may nevertheless raise questions regarding firm selection into the giant network. We therefore account for such concerns more explicitly in regression analysis below. ${ }^{19}$

\footnotetext{
${ }^{19}$ The magnitude of the effect on bank credit and financial distress in figures is smaller than in the regressions later on because the graph only utilizes the smaller sample of "single entry" and "single exit" firms for whom a timeline makes sense. The regressions utilize the full sample by also including firms that enter/exit more than once.
} 


\section{A. Effect on External Finance}

Column (1) in Table II estimates specification (3) with firm and date fixed effects. The dependent variable is $\log$ of total external credit of a firm, ${ }^{20}$ and the sample is restricted to non-defaulting firms since we are interested in measuring the active borrowing of a firm. The inclusion of firm fixed effects implies that the value of the giant-network entry is an estimate for firms that change their giant-network membership status sometime during our sample period. The entire sample is needed for estimation in order to appropriately estimate time effects and their interactions with firm-type variables.

Column (1) shows that when a firm is in the giant network, it is able to increase its borrowing by 16.6 percent compared to when the same firm is out of the giant network. Table I showed that the cross-sectional differences between firms that are in the giant network versus those that are not in any network are much larger. This difference illustrates the importance of controlling for time-invariant firm specific attributes that co-determine giant-network membership and credit market outcomes. Nonetheless, the value generated by the network is substantial even once such selection is accounted for.

We should note that this impact of network membership could reflect an increase both in the demand for credit by a firm and in the supply of credit from a bank. On the demand side, entry into the giant network potentially provides firms with important business opportunities, credible market information, and effective contractual enforcement, which in turn should increase firm productivity and demand for credit. On the supply side, banks may be more willing to lend to firms with network connections because such connections provide banks with credible information about firms and enable better monitoring. While some of our subsequent results hint at the relative importance of these two channels, we want to emphasize that separating the supply and demand channels is beyond the scope of this paper. The focus instead is on trying to obtain a causal estimate of the net effect of entering the giant network, whether driven by changes in the demand for or supply of credit.

Column (2) adds size decile, industry, and firm city location fixed effects, all interacted with time fixed effects to non-parametrically absorb time-varying shocks at these levels. The estimated effect of network entry is robust to the inclusion of these controls (over 230 dummies in addition to the 100,000 firm fixed effects). Column (3) takes this a step further by also non-parametrically controlling

\footnotetext{
${ }^{20}$ We set this value to zero when a firm is not borrowing. Excluding these observations provides qualitatively similar results.
} 
for network size effects. Recall, in our earlier discussion, we had noted that entrants are likely to be in small networks prior to giant-network entry and that this may both impact their likelihood of entry and subsequent performance. The specification in Column (3) addresses this concern by only comparing entrants to non-entrants who have exactly the same network size as the entrant did before it joined the giant network. We do so by including fixed effects for a firm's network size (when it is not in the giant network) interacted with time dummies (resulting in over 400 additional dummies). While this is a very demanding specification, as the results in Column (3) show, adding these controls gives almost identical results (0.19).

The coefficient on network entry in Table II is identified off of the 2,457 firms that change their network membership during our sample period. Column (4) makes this explicit by first demeaning the data using all of the fixed effects in Column (1) and then estimating the network entry effect on the demeaned data using only the 2,457 firms that change network membership status. Column (5) does the same but first demeans the data using all the fixed effects and their interactions in Column (2).

Column (6) supplements Column (2) by including a firm's lagged borrowing growth as a control. As explained in the methodology section, doing so addresses selection concerns that may arise if firms already on an upward trajectory are more likely to enter the giant network. If this were the case then including lagged loan growth should reduce or eliminate the estimated coefficient on network entry. However, Column (6) shows that including lagged growth in bank credit does not change the estimated coefficient on network entry. The small positive sign on lagged borrowing growth suggests that, while there is positive serial correlation in loan growth, it is not differentially higher for firms that enter the giant network.

Column (7) implements the instrumental variable approach by separately estimating the impact of giant-network membership on "incidental" entrants/exitors. We do so by creating a dummy variable "direct entrant/exitor" and interacting it with InNetwork. Direct entrant/exitor is one if a firm enters/exits the network directly and zero if it enters/exits incidentally. Thus the coefficient on the InNetwork term reflects the value of being in the network on the incidental entrants (the analogous instrumental variable estimate). As explained in the methodology section, incidental entrants/exitors are less likely to suffer from endogenous entry/exit concerns since they are entering/exiting because of another firm's decision. 
The results in Column (7) show that the effect of network membership on firms that enter/exit incidentally is large and significant. While the magnitude of network membership on incidental entrants is smaller, the difference between incidental and direct entrants is not statistically significant. Moreover, as explained earlier, since the IV is a LATE estimator, some of the change in coefficient magnitude may be attributed to underlying heterogeneity in the treatment effect. One obvious candidate for such heterogeneity is the fact that (almost by construction) incidental entrants and exitors connect with the giant network in a weak manner (i.e., their Google PageRank measure when in the giant network is statistically smaller than that of direct entrants). Moreover, they may also differ in their average network strength when they are not part of the giant network.

We can test whether such heterogeneity affects the magnitude of the IV estimate by appropriately controlling for the heterogeneity of the treatment effect by the strength of firm's connection to the giant network. This is done in Column (8), which accounts for treatment effect heterogeneity by interacting InNetwork separately with the Google PageRank of a firm when it is in the giant network and when it is out of the giant network. The magnitude of the interaction terms becomes even smaller, suggesting that there is little difference in the network entry effect between direct and incidental entrants/exitors that have similar power measures (network size, etc.) when they were out of and connect to similar (in terms of link strength) parts of the giant network. We will examine the nature of the heterogeneity in more detail below, but for now the important point to note is that the similar effects for direct and incidental entrants provides evidence that time-varying selection concerns are not substantial and that even the estimates on direct entrants are likely to be therefore unbiased. For this reason, in subsequent specifications that examine robustness, potential channels, and treatment heterogeneity, we will not separate the estimates for direct and incidental firms. ${ }^{21}$

\section{B. Effect on Financial Viability}

Table III repeats the analysis of Table II using financial distress as the outcome variable. The number of observations in Table III is larger because it includes observations for firms that are currently in default.

Column (1) estimates the basic specification with firm and time fixed effects. The propensity to

\footnotetext{
${ }^{21}$ We have run these specifications separately for incidental firms as well. As expected, we find similar effects, although of somewhat weaker statistical significance given that we are dropping around half of the relevant firms that are used to identify the network effect.
} 
enter financial distress decreases by 1.7 percentage points when a firm is part of the giant network. Given the average default rate for firms that enter or exit the network, the drop in financial distress represents about a 9.5 percent improvement. Column (2) controls for shocks at the size, industry, or location level at any point in time by including firm type interacted with time fixed effects and shows little change in the estimates. Column (3) shows the results are robust to adding fixed effects for a firm's network size (when it is not in the giant network) interacted with time dummies. Columns (4) and (5) restrict to the sample of firms that actually change their network membership during our sample period and, as expected, show that the results hold.

Column (6) includes lagged changes in financial distress, ${ }^{22}$ and Column (7) provides the analogous IV estimates by separately estimating the effect for incidental entrants/exitors. In this case, the effect on direct entrants is similar to that for incidentals even without adjusting for treatment heterogeneity (it also remains similar if we account for treatment heterogeneity), again suggesting that time-varying selection is not a serious concern in this case.

Taken together, the results in Tables II and III show that membership into the giant network is beneficial for firms in terms of increasing bank credit and improving financial viability. Given our controls, such as firm fixed effects and firm-type interacted with time fixed effects, as well as our focus on firms that enter/exit due to incidental factors and the evidence against substantial timevarying selection, we can better interpret these results as reflecting a causal impact of giant-network membership on a firms' credit access and default performance.

\section{Robustness to network definition}

Our results thus far were based on networks constructed by joining two firms if they have a director in common. One could question whether these results are driven by our particular choice of network definition. Section I.B and the appendix highlight some alternative definitions of network formation and show the emergence of a giant network in all definitions. We now show that the results of Tables II and III continue to hold under these alternative network definitions.

\footnotetext{
${ }^{22}$ The observations decrease when we use lag change in default rate since a firm may not have been borrowing during the previous periods. While somewhat arbitrary, one could alternatively interpret these observations as a firm not defaulting. Doing so provides very similar estimates (-1.39 vs. -1.63$)$.
} 
We first reconstruct networks after dropping all those directors that are nominated by the government to sit on boards. These directors, identified as those who are on the boards of government firms, constitute 5 percent of directors in the giant-network firms. Government directors may sit on the board of a firm for a couple of reasons. The government may appoint directors if a firm borrows significant capital from development finance institutions owned by the government or if the firm belongs to an industry regulated by the government.

The removal of government directors for the purpose of network formation could be justified if government directors reflect the ability of a firm to access government financial institutions rather than an informal business network. Similarly, a single government director sitting nominally on the board of many firms may artificially create a large pool of interconnected firms. The size of the giant network reduces from 5,295 firms to 4,782 firms once we exclude such directors. However, repeating our main regressions with bank credit and financial distress as outcome variables in Columns (1) and (2) of Table IV shows that our results are similar when excluding government directors.

Our second robustness check is the exclusion of directors that are not reported as owning any equity in the company. One could argue that the benefit of network is only passed on through links which actually involve a real stake in the company, and so one should only consider such links. Since the ownership information for directors is often missing, we lose about 45 percent of directors in applying this restriction, and the resulting giant network is much smaller, consisting of 2,010 firms. However, Columns (3) and (4) show that restricting attention to this definition of network links gives us very similar results.

Finally, Columns (5) and (6) radically change our definition of network formation by only counting links between firms if the firms have at least two directors in common. In other words, links have to be very strong between firms in order for firms to qualify as being connected to each other. The resulting giant network has 1,668 firms. This stronger definition of networks provides larger estimates, particularly for bank credit, showing that the benefit of entry into the giant network is even stronger if a firm enters through stronger links (i.e., with at least two directors in common) and connects to a giant network which itself is connected through stronger links.

In addition to these alternative definitions, we also checked and confirmed the robustness (regressions not shown) of our results in Tables II and III to forming networks by excluding: (i) firms with single directors; (ii) small firms in terms of borrowing; and (iii) firms with missing national identity 
card information (and therefore less accurate matches). The former two checks ensure that our results are not affected by less (economically) significant firms, and the latter that the findings are not sensitive to the matching algorithm used.

\section{Who provides the increase in external finance?}

Columns (1) and (2) in Table V test whether the increase in bank credit due to entry into the giant network is driven by the intensive or extensive margin. Column (1) looks at the intensive margin and finds that the average loan size from an existing bank increases by about 14 percentage points for a firm entering the giant network. Column (2) investigates the extensive margin and finds that entry into the giant network also leads to an increase of 0.13 banks per firm. Since the average entrant has 1.2 banking relationship prior to entry, the estimated effect represents a 10 percent increase in the number of creditors.

The banking environment in emerging economies is often susceptible to political pressures, and there is evidence from Pakistan that this is especially true for lending by government banks (see Khwaja and Mian, 2005). Consequently, one possible rationale for the increase in bank credit is access to political connections. If this were the case, one would expect the increase in bank credit due to giant-network entry to largely come from government banks. However, Column (3) shows that this is not the case. The percentage of credit from government banks declines by 1.4 percent after giant-network entry. ${ }^{23}$

The increase in credit to firms that enter the giant network is due to private domestic banks. Column (4) shows that the increase in percentage of credit coming from private domestic banks is 2.5 percent and significant. The remaining category of banks is foreign banks. Firms' share of financing coming from foreign banks declines slightly but is not significant. Thus, the large increase in bank credit due to giant-network entry is coming largely from private domestic banks, whose market share significantly increases relative to government banks post entry. These results suggest that entry into the giant network leads to real informational and enforcement gains that generate higher credit for borrowing firms. This view is also consistent with our earlier finding that default rates decline after gaining membership in the giant network.

\footnotetext{
${ }^{23}$ In specifications (not shown), we also find that the impact of network membership is not affected/varying by political links, suggesting that political ties have less of a role to play in this case.
} 
One information/enforcement based explanation for the increase in bank credit due to network entry is that banks are more willing to lend to a firm if they already have a relationship with the firm's new network neighbors. If so, we should see a disproportionate share of the credit from new lenders coming from its neighbors' banks. Column (5) tests this prediction.

We construct a measure that captures the relative share of additional credit coming from an entering firm's new network neighbors. This variable is zero when a firm is out of the giant network. When a firm enters, the variable is constructed as follows: Let $A$ be the total credit coming from all new banking relationships post network entry. Let $B$ be the total credit coming only from those new banking relationships, where the bank is an existing creditor of one of the new neighboring firms of the entrant. Then $\frac{B}{A}$ captures the share of credit coming from those first-time lenders who already have a relationship with the entering firm's new neighbors. We normalize this ratio by subtracting what it would have been if new banking relationships were formed at random. This "random chance" ratio, $\frac{\bar{B}}{\bar{A}}$, is the total lending portfolio of all new banks lending to an entering firm' neighbors (but not the firm itself) divided by the total lending portfolio of all banks the firm was not borrowing from before. The normalized ratio, $Y=\left(\frac{B}{A}-\frac{\bar{B}}{\bar{A}}\right)$, forms the dependent variable in Column (5). Since $Y$ is only defined for firms that are part of the giant network, the data is restricted to firms that are part of the giant network at some point in time.

If a disproportionate amount of credit from new banking relationships comes from a firm's new neighbors, then $Y$ should be positive post entry. Column (5) shows that this is indeed the case: Firms borrow a 12 percentage points larger share of new credit from their neighbors' banks over and above what they would have had they borrowed proportionally to bank size.

\section{E. Heterogeneity in Network Benefits}

The theoretical literature on networks emphasizes that network benefits are unlikely to be equally shared. Benefits are likely to vary based on an entrant's pre-existing power and where in the network it is connected to. For example, if an entrant connects to a more "powerful" node, network benefits are likely to be larger. Similarly, an entrant which started off with more power may gain more (less) from entry into the giant network if the giant network acts as a complement (substitute) to the firm's preexisting power. An advantage of our data set is that we can measure the intra-network heterogeneity in the power of connections. This gives us the unique opportunity to test whether benefits to network 
membership depend on the power of the node that a firm connects to and whether the network acts as a complement or substitute to the firm's pre-entry power.

As described earlier, we construct the power measures separately for when a firm is in and out of the giant network. ${ }^{24}$ The coefficient on the former interacted with giant-network entry shows how much a firm gains when it enters at a more powerful point in the network. The coefficient on the interaction of the out-of-network firm power measure and network entry estimates whether a firm with relatively more powerful connections ex ante gains more (if membership is a complement) or less (if membership is a substitute) from the network.

Table VI presents the results for firm borrowing. The power measures are standardized for interpretational ease. Columns (1) through (4) show that regardless of the measure of power used, an entrant gains more when it connects to a more powerful node in the network. There is also consistent evidence for the "networks-as-substitutes" idea: Firms that are more powerful to begin with tend to gain relatively less when they enter the giant network. The magnitude of these effects is economically significant. For example, connecting to a node that is one standard deviation stronger in terms of its "Google PageRank" leads to an almost 17 percentage points greater increase in bank credit. In contrast, a firm with a standard deviation greater pre-entry Google PageRank gains 14 percentage points less from the giant network.

Table VII repeats the exercise with financial distress as the dependent variable. Unlike access to credit, whether or not a firm connects to more powerful nodes does not matter for financial distress. Moreover, in sharp contrast to the results on borrowing, network membership appears to be a complement to a firm's pre-existing "power" when examining financial distress: Firms that are more powerful initially see a greater drop in default rates when they enter the giant network.

While Tables VI and VII show that network value indeed varies by the power of the nodes to which a firm connects as well as by its pre-existing power, it also highlights that this heterogeneity may be quite different depending on which outcomes that one conciders and those mechanisms which are generating network value. While it is hard to isolate a precise mechanism, the previous results suggest that a firm's borrowing relies more on the networks strength vis-à-vis lenders (and hence the giant network's access to credit acts as a substitute for pre-existing firm power). In contrast, a firm's ability to avoid financial distress may depend relatively more on whether a firm is powerful enough

\footnotetext{
${ }^{24}$ These measures are typically not zero even when a firm is out of the giant network since such firms are often in smaller networks when they are not part of the giant network.
} 
to seek insurance from other firms in its network. The latter suggests exploring possible insurance benefits more directly.

\section{F. The Insurance Benefits of Networks}

A commonly perceived benefit of networks and informal connections is that they help firms insure each other against common shocks (Khanna and Yafeh, 2005). Networks may do so by providing access to neighbor's internal capital markets through instruments such as trade credit. Alternatively, networked firms may insure each other by giving preferential treatment in awarding contracts. Such preferential treatment can curtail losses due to business cycle fluctuations. Finally, to the extent that networks improve overall productivity of a firm, membership can lower sensitivity of firm performance to common shocks.

We test for the insurance benefits of network membership in Table VIII. We examine how networked firms respond to economic shocks hitting their industry or city relative to non-networked firms. The test is carried out by first constructing common shocks hitting an individual firm at a point in time. Common shocks are defined as aggregate changes in financial distress (default rate) at the level of a firm's city and industry. To the extent that a firm is affected by shocks to its city or business cohort, its default rate will positively co-vary with its cohorts' shocks. The test of whether the network provides insurance is if the default rate of firms that are members of the giant network co-varies less with their city and industry cohorts' shocks. Since this test requires us to estimate covariances, in the first two specifications, we make use of the full loan level data (1996 to 2003) rather than only restricting to those quarters where we have firm-director information. We are able to do so by extending our definition of whether a firm is in the giant network or not to previous quarter by assuming its status is the same over time. For example, if it's always in the giant network during 1999-2003, we assume it's always in during 1996-1998 as well. In all specifications, we include firm fixed effects to account for unobserved (level) differences across firms and time fixed effects to absorb any secular time trends.

Column (1) runs this test and reveals some striking results. While non-networked firms are 56 and 63 percent more likely to default if their city and business cohort default, respectively, networked firms are entirely immune to their cohort firms' shocks. Column (2) focuses separately on the giant-network firms that exit and enter the network during our data period (i.e., the 2,457 firms in Column (3) of Table II) and shows the same, though slightly smaller, insurance patterns for these firms. 
Columns (3)-(4) restrict the sample to only the 1999-2003 period to address a potential selection concern. If firms are selected into networks precisely because they are the types of firms that are better able to insure themselves against shocks, then the results in Columns (1) and (2) may be picking up such select firms. One way to address these concerns is to again take advantage of firms entering and exiting the network and to ask whether the same firm is more insured when it is in the giant network as compared to when it is not. This implies restricting the data to the quarters (1999-2003) where we have director information. ${ }^{25}$ Since the insurance test relies on estimating how shocks co-vary, the shorter time series due to this data restriction is likely to adversely affect our ability to estimate these covariances.

Thus, Column (3) first shows the impact of the sample restriction by re-estimating Column (2) in the restricted sample. While the city shock insurance effect remains, we see that the sample drop results in a much weaker business-cohort insurance effect. Nevertheless, Column (4) runs the test and shows that, for shocks to their city cohorts, a firm is better insured when it is in the giant network compared to when it is not. This suggests that the insurance results are not likely to be driven by selection but by the value generated from being a member of the giant network.

\section{Concluding Remarks}

A key advantage of our data set is that it provides the opportunity to observe connections between firms in practically the entire economy. We can thus construct a comprehensive topology of networks, estimate network value, and explore how it varies by the strength of connections. Using time-series variation in network membership for a given firm and focusing on incidental entrants and exitors provides further confidence that our results reflect the direct impact of network membership itself.

Our empirical results are also helpful in discriminating between possible theories of why networks matter. The fact that network benefits depreciate quickly when firms exit, suggest that networks are not just useful as a signalling device (of firm quality). If that were the case, network benefits should persist even when firms exit. Thus credible leverage vis-a-vis network partners in the form of cross-reliance through common directors is important for network benefits. This interpretation is further bolstered by the finding that increased banking access through network membership is driven

\footnotetext{
${ }^{25}$ While we could plausibly impute whether a firm is of the type that enters/exits the giant network over time to previous quarters (as we did in Column (2)), it would be far less precise to impute whether such a firm is actually in or out in a particular quarter without having actual directorship data for that quarter.
} 
primariy through those private banks that are already lending to network neighbors.

Network membership provides tangible benefits in the form of access to bank credit, and the extent of these benefits depends on the strength with which a firm is connected to the network. However, we are circumspect regarding the welfare implications of our results. Networks can facilitate transactions by substituting away market failures such as informational asymmetry and weak contractual enforcement. However, if entry into the network is biased in favor of people with a particular background, then networks may impeded long-run growth by excluding large segments of population from productive enterprise. The potential dark side of networks is an exciting area of research ${ }^{26}$.

\footnotetext{
${ }^{26} \mathrm{~A}$ couple of recent papers documenting the negative effect of networks include Bertrand et al 2002 and Bertrand et al 2008 .
} 


\section{Appendix: Structure of the "Giant Network"}

The appendix describes the structure of the giant network in more detail and conducts some further robustness checks. A more detailed presentation is in Khwaja et al. (2008)

\section{A. Network Definition Robustness}

In the paper, we link two firms if they have at least one director in common. In order to check the robustness of this definition, we also explore three alternative ways of defining links between firms. The results show that the general network pattern holds. There is always a giant network that is orders of magnitude larger than the next network. We have already shown in the paper that all our key results hold when using alternative definitions for giant network. The three alternate link definitions used are:

(i) Excluding government directors: We recompute the network structure after dropping all government directors. Appendix Figure II (Panel A) shows that there is no appreciable change in the structure of the giant network. Moreover, it is still 100 times higher than the second largest group and accounts for over 50 percent of total lending in the economy.

(ii) Excluding all directors in a firm who do not hold equity in the firm: Panel B in Appendix Figure II shows the structure of giant network computed after dropping all directors who do not own equity in the firm. The giant network reduces somewhat in size but still includes 4.5 percent of the firms in the database and over 40 percent of total lending.

(iii) Link two firms only if they have at least two directors in common: Given how demanding this definition is, it significantly increases the fraction of firms that have no links, with over 90 percent of the firms no longer (double-)linked to any other firm. Nevertheless, the structure of the network remains fairly stable (Panel C, Appendix Figure II). While smaller, it still includes over 2,000 firms that borrow over 50 percent of total lending.

\section{B. Giant-Network Structure}

We look at the giant network and see if there are any "giant directors," (i.e., directors who hold positions on a very large number of firms). We find few such directors. Less than 1 percent of the directors sit in the boards of more than 10 firms, and 78 percent of the directors are appointed to the board of just one firm. While there are directors who serve on the boards of several different firms - some of them sit in over 60 different boards - this by itself doesn't explain the size of the giant network. As we show below, removing such directors still keeps the giant network intact.

We can repeat the same exercise to see whether there are "royal firms" that are connected to lots of other firms and whether such firms can explain the giant-network structure. The most connected firm has direct links with 215 firms in the network. However, most of the firms have links with only a few others. Of giant-network firms, 75 percent have links with less than 10 firms. Even the highly connected firms are not crucial since the giant-network structure survives even if we exclude these firms.

\section{Some more small world properties of the giant network}

We discussed the "small world" nature of the giant network in Section I.B. The small world and highly connected nature of the giant network can further be illustrated through Appendix Figure III. The figure chooses a typical central node (with only six immediate neighbors) and finds that this node can connect to virtually the entire giant network within only five steps (with each step being an additional radius of the node's neighbors). Since we can move from one firm to all other giant-network 
firms in such a small number of steps, there is a lot of path redundancy and multiplicity of pathways connecting any two firms.

These small world properties of the giant network suggest that there should be no "critical" nodes or groups of nodes that hold the entire giant network together. In other words, the overall structure of the giant network should be robust to the removal of directors that sit on a high number of firms, or alternatively, to the removal of firms that have a high number of links. We conduct some tests and verify this property to be true.

Let $X$ be the number of firms' boards on which a given director sits. We simultaneously removed directors with an $X$ above a threshold and recompute the network structure. We start with a threshold value of fifty-one and lowered it in steps of two. The giant network does not break until we drop all directors that sit on the boards of three or more firms. The remarkable thing to note is that, even if we drop all directors who sit on the boards of five or more firms, while this does result in several smaller networks, we still find that there is one giant network that has 63 percent of the original giant-network firms and that borrows 52 percent of total lending.

In an analogous exercise, we dropped all firms above a certain threshold in terms of how many other firms they are linked to. We start with a threshold of dropping firms with more than 202 links and lower the threshold in steps of 10. Each time, we recomputed the network structure after dropping the firms. The giant network remains even when we drop the top 500 firms (with links to 32 or more firms). It is only when we drop all firms that are linked to 12 or more firms that we observe a significant reduction in the giant network.

These checks show that the small-world properties of the giant network make it highly robust to the removal of firms/directors. Thus, regardless of the shocks the economy faces, the giant network remains salient. 


\section{References}

Albert, Reka and Albert-Laszlo Barabasi, Statistical mechanics of complex networks, Reviews of Modern Physics, Vol 74, January 2002

Banerjee, A., and K. Munshi, 2004. "How Efficiently is Capital Allocated? Evidence from the Knitted Garment Industry in Tirupur." Review of Economic Studies 71(1):19-42.

Belleflamme, P., and F. Bloch. 2002. "Market Sharing Agreements and Stable Collusive Networks" mimeo: University of London and GREQAM.

Burt, R.S. 1992. "Structural Holes: The Social Structure of Competition." Cambridge, MA: Harvard University Press.

Bertrand, Marianne; Paras Mehta and Sendhil Mullainathan, 2002. "Ferreting Out Tunneling: An Application To Indian Business Groups," The Quarterly Journal of Economics, MIT Press, vol. 117(1), pages 121-148, February

Bertrand, Marianne; Simon Johnson, Krislert Samphantharak, and Antoinette Schoar, 2008. "Mixing family with business: A study of Thai business groups and the families behind them", Journal of Financial Economics.

Cohen, Lauren; Andrea Frazzini and Christopher Malloy, 2008. "The Small World of Investing: Board Connections and Mutual Fund Returns", Journal of Political Economy, 116, 951-979.

Calvo-Armengol, A., and M.O. Jackson. 2001. "Social Networks in Determining Employment: Patterns, Dynamics, and Inequality," forthcoming: American Economic Review,

Casella, Alessandra, and James Rauch. 2001. "Networks and Markets." Journal of International Economics, 61(1): 249-52.

Erdos, P., and A. Renyi, 1959, Publ. Math. (Debrecen) 6, 290.

Erdos, P., and A. Renyi, 1960, Publ. Math. Inst. Hung. Acad. Sci. 5, 17.

Fisman, R. and T. Khanna. 2004. "Facilitating Development: the Role of Business Groups". World Development, vol. 32, issue 4, pages 609-628

Feenstra, R., T.-H. Yang, and G.G. Hamilton. 1993. "Market Structure and International Trade: Business Groups in East Asia." (ITI). NBER Working Paper, 4536.

Granovetter, M.S. 1973. "The Strength of Weak Ties.” American Journal of Sociology, 78: 1360-1380

Grief, Avner. 1993. "Contract Enforceability and Economic Institutions in Early Trade: The Maghribi Traders' Coalition." American Economic Review, 83(3): 525-48.

Hochberg, Yael; Ljungqvist, Alexander and Yang Lu. 2007. "Whom You Know Matters: Venture Capital Networks and Investment Performance." Journal of Finance, 57(1).

Hoshi, T., A. Kashyap, and D. Scharfstein. 1991. "Corporate Structure, Liquidity, and Investment: Evidence from Japanese Industrial Groups." Quarterly Journal of Economics, 106: 33-60.

Imbens, G., and J. Angrist (1994), "Identification and Estimation of Local Average Treatment Effects," Econometrica, Vol. 61, No. 2, 467-476. 
Jackson, Matthew. 2004. "A Survey of Models of Network Formation: Stability and Efficiency," Chapter 1 in Group Formation in Economics; Networks, Clubs and Coalitions, ed. Gabrielle Demange and Myrna Wooders, Cambridge University Press, Cambridge U.K.

Jackson, M.O. and A. Wolinsky. 1996. "A Strategic Model of Social and Economic Networks." Journal of Economic Theory, 71: 44-74.

Jackson, M and B. Rogers. 2005. "The Economics of Small Worlds," Journal of the European Economic Association, MIT Press, vol. 3(2-3), pages 617-627, 04/05.

Johnson, C. and R.P. Gilles. 2000. "Spatial Social Networks," Review of Economic Design, 5: 273-300.

Khanna, T. and Y. Yafeh. 2005. "Business Groups and Risk Sharing around the World. Journal of Business, vol. 78. No. 1.

Khanna, T. 2000. "Business Groups and Social Welfare in Emerging Markets: Existing Evidence and Unanswered Questions." European Economic Review, 44: 748-61.

Khwaja, A. I., and Atif Mian. 2005. "Do Lenders Favor Politically Connected Firms? Rent Provision in an Emerging Financial Market" Quarterly Journal of Economics, Vol. 120, Issue 4, November.

Khwaja, A. I., A. Mian, A. Qamar (2008). "Identifying Business Networks in Emerging Economies," Working Paper.

Kranton, R. and D. Minehart. 2001. "A Theory of Buyer-Seller Networks," American Economic Review, 91(3): 485-508.

Lamoreaux, N. 1986. "Banks, Kinship and Economic Development: The New England Case." Journal of Economic History, 46(3): 647-67.

Leff, N. 1976. "Capital Markets in the Less Developed Countries: The Group Principle." Money and Finance in Economic Growth and Development. New York: Marcel Dekker, Inc. 97-122.

Leff, N. 1979. "Entrepreneurship and Economic Development: The problem Revisited." Journal of Economic Literature, 17(March):46-64.

McMillan, J., and C. Woodruff. 1999.: "Inter-firm Relationships and Informal Credit in Vietnam," Quarterly Journal of Economics, pp. 1285-1320.

Mintz, B. and M. Schwartz. 1985. The Power Structure of American Business. Chicago: University of Chicago Press.

Mobius, M and A. Szeidl. 2007. "Trust and Social Collateral". Working Paper.

Stokman, F., R. Ziegler, and J. Scott (eds). 1985. "Networks of Corporate Power: An Analysis of Ten Countries." Cambridge: Polity Press.

Scott J. 1987. "Intercorporate Structures in Western Europe: A Comparative Historical Analysis of Business." In Intercorporate Relations The Structural Analysis of Business, ed. M. Mizruchi and M. Schwartz, 208-232. New York: Cambridge University Press.

Uzzi, B. 1999: "Embeddedness in the Making of Financial Capital: How Social Relations and Networks Benefits Firms Seeking Financing," American Sociological Review.

Watts, D. J., and S. H. Strogatz (1998). "Collective Dynamics of 'Small-World' Networks," Nature, CCCLXXXXIII, 440. 


\section{Table I \\ Summary Statistics}

This table presents statistics based on 105,917 firms' connections to the giant network. Panel A separates firms into four categories: (1) "Always In" - firms that are always in the giant network; (2) "In-Out" - firms that are in the giant network at some but not all time during our sample period (4 years); (3) "Other Networked" - firms which are never in the giant network but are part of smaller networks with network size varying from 2 to 85 firms; and (4) "Non-Networked" - firms which never share directors with any other firms. Panel B examines how different measures of firm power change for firms moving in and out of the giant network. Measures of power include the number of neighbors a firm has, the number of these neighbors' directors, the number of lenders these neighbors have, and the firm's own Google PageRank (the Google PageRank is a power measure we construct based on the Google PageRank algorithm).

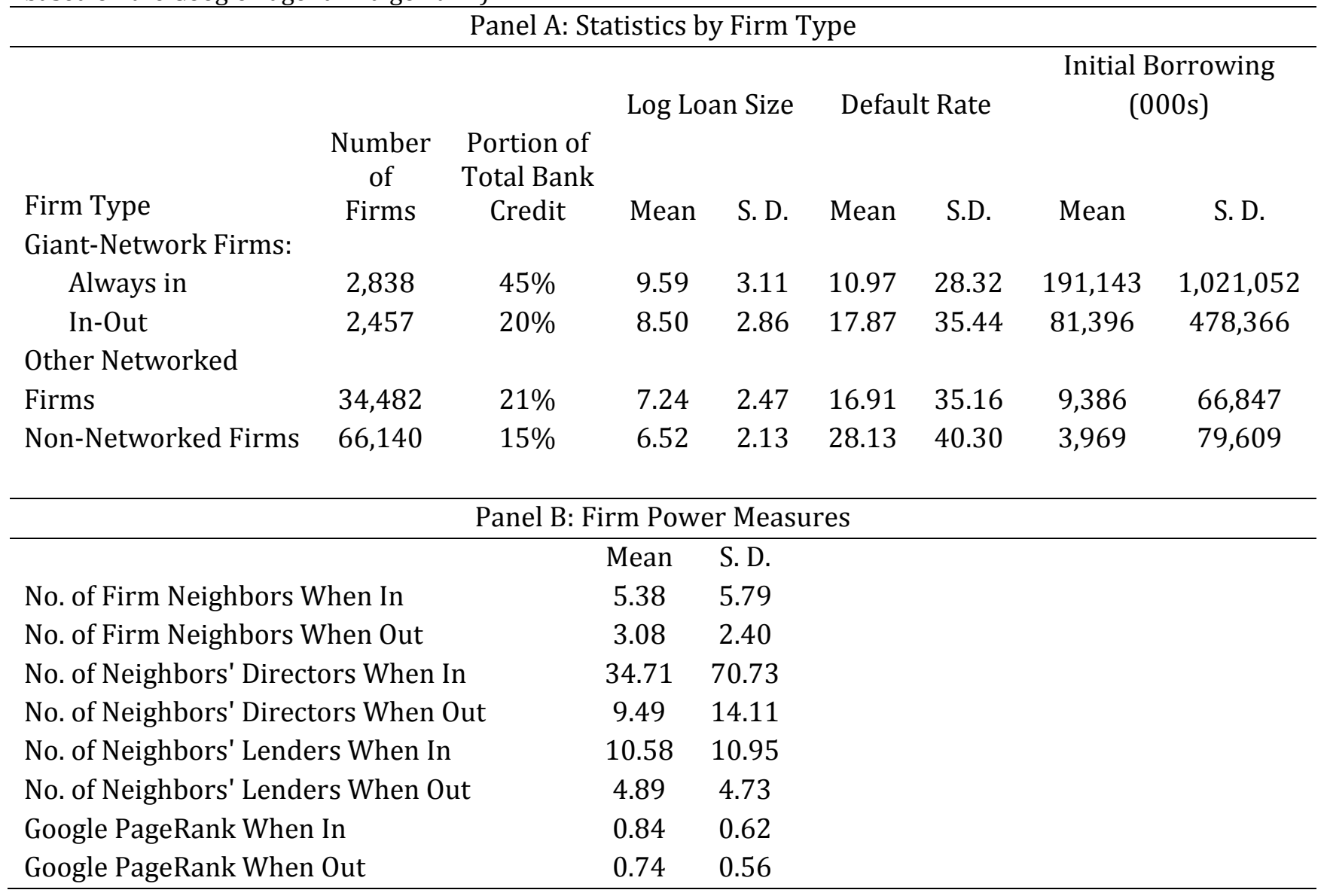




\section{Table II}

\section{The Effect of Giant-Network Entry On Firm Borrowing}

This table shows the effect of network membership on firm borrowing. The dependent variable is log of firm borrowing, and the sample is restricted to non-defaulting firms. Columns (1)-(3) and Columns (6)-(8) include all firms in the sample. Columns (4)-(5) replicate Columns (1)-(2) in the restricted sample of firms that move in and out of the giant network. "Basic" fixed effects are firm and time fixed effects. "Expanded" fixed effects include firm and time fixed effects, as well as size decile, industry, and firm city location fixed effects, all interacted with time fixed effects. "In Network?" is a dummy variable equal to one when a firm is in the giant network and equal to zero when it is not. "Direct Entrants" are firms that enter (or exit) the giant network directly (i.e. either one of their directors joins (or leaves) the board of a giant-network firm, or a giant-network director joins (or leaves) its board). ${ }^{* *},{ }^{* *}, *^{*}$ indicate coefficients statistically distinct from 0 at the $1 \%, 5 \%$, and $10 \%$ levels, respectively. Robust standard errors are in brackets.

\begin{tabular}{|c|c|c|c|c|c|c|c|c|}
\hline & $(1)$ & $(2)$ & (3) & (4) & (5) & (6) & (7) & (8) \\
\hline In Network? & $\begin{array}{c}0.166^{* * *} \\
(0.043)\end{array}$ & $\begin{array}{c}0.184^{* * *} \\
(0.043)\end{array}$ & $\begin{array}{c}0.191^{* * *} \\
(0.055)\end{array}$ & $\begin{array}{c}0.154^{* * *} \\
(0.043)\end{array}$ & $\begin{array}{c}0.177^{* * *} \\
(0.043)\end{array}$ & $\begin{array}{c}0.183^{* * *} \\
(0.043)\end{array}$ & $\begin{array}{l}0.128^{* *} \\
(0.059)\end{array}$ & $\begin{array}{c}0.168^{* * *} \\
(0.062)\end{array}$ \\
\hline Lagged Loan Growth & & & & & & $\begin{array}{c}0.012^{* * *} \\
(0.002)\end{array}$ & & \\
\hline $\begin{array}{l}\text { (In Network?) * (Direct } \\
\text { Entrant) }\end{array}$ & & & & & & & $\begin{array}{c}0.126 \\
(0.085)\end{array}$ & $\begin{array}{c}0.024 \\
(0.090)\end{array}$ \\
\hline $\begin{array}{l}\text { (In Network?) * (Google } \\
\text { Rank When In) }\end{array}$ & & & & & & & & $\begin{array}{c}0.164^{* * *} \\
(0.044)\end{array}$ \\
\hline $\begin{array}{l}\text { (In Network?) * (Google } \\
\text { Rank When Out) }\end{array}$ & & & & & & & & $\begin{array}{c}-0.134^{* * *} \\
(0.048)\end{array}$ \\
\hline Fixed Effects & Basic & Expanded & $\begin{array}{l}\text { Expanded } \\
\text { Plus } \\
\text { Network } \\
\text { Size*Time }\end{array}$ & Basic & Expanded & Expanded & Expanded & Expanded \\
\hline $\mathrm{N}$ & 286,034 & 286,034 & 285,305 & 12,053 & 12,053 & 286,034 & 286,034 & 286,034 \\
\hline $\mathrm{R}^{2}$ & 0.59 & 0.60 & 0.60 & 0.44 & 0.36 & 0.60 & 0.60 & 0.6 \\
\hline
\end{tabular}




\section{Table III}

The Effect of Network Entry On Firm Financial Distress

This Table shows the effect of network membership on firm financial distress. The dependent variable is default rate. Columns (1)-(3) use the full sample of firms, while Columns (4)-(5) replicate Columns (1)-(2) in the restricted sample of firms that move in and out of the giant network. The number of observations reduces in Columns (6) and (7) because of the inclusion of lagged growth which is, by construction, missing for firms in their first period of data. "Basic" fixed effects are firm and time fixed effects. "Expanded" fixed effects include firm and time fixed effects, as well as size decile, industry, and firm city location fixed effects, all interacted with time fixed effects. "In Network?" is a dummy variable equal to one when a firm is in the giant network and equal to zero when it is not. "Direct Entrants" are firms that enter (exit) the giant network directly, i.e. either one of their directors joins (leaves) the board of a giant-network firm, or a giant-network director joins (leaves) its board. ${ }^{* * *},{ }^{* *},{ }^{*}$ indicate coefficients statistically distinct from 0 at the $1 \%$, $5 \%$, and $10 \%$ levels, respectively. Robust standard errors are in brackets.

$(1)$

In Network?

Lagged Default Rate Growth

(In Network?) * (Direct

Entrant)

Fixed Effects
(2)

(3)
(5)

$-1.689 * * *$
$(0.349)$

$(0.349)$

\section{$(0.351)$}

$(0.350)$
(4)

$-1.62^{* * *}$
$(0.348)$

$(0.348)$
(0.407)
$0.167^{* * *}$

(6)

(7)

(0.004)

Expanded

Plus

Network

Basic

Size*Time

\begin{tabular}{cc} 
Expanded & Size*Time \\
\hline 397,416 & 396,581
\end{tabular}

Basic

Expanded

Expanded

Expanded

$\mathrm{N}$

397,416

0.86

0.86

0.1

15,043

254,576

397,416

0.86 


\section{Table IV}

\section{Alternative Network Definitions}

This table shows the robustness of the network membership effect to different definitions of network construction. Definition A excludes all government directors. Definition B uses a network definition that excludes directors who do not own equity in their firms. Definition C examines networks where links are made between firms only if they have two or more directors in common. Definition D excludes firm with single directors when forming links. "Expanded" fixed effects include firm and time fixed effects, as well as size decile, industry, and firm city location fixed effects, all interacted with time fixed effects. "In Network?" is a dummy variable equal to one when a firm is in the giant network and equal to zero when it is not. $* * *, * *, *$ indicate coefficients statistically distinct from 0 at the $1 \%, 5 \%$, and $10 \%$ levels, respectively. Robust standard errors are in brackets.

\begin{tabular}{|c|c|c|c|c|c|c|}
\hline & \multicolumn{2}{|c|}{ Definition A } & \multicolumn{2}{|c|}{ Definition B } & \multicolumn{2}{|c|}{ Definition C } \\
\hline & (1) & $(2)$ & (3) & $(4)$ & (5) & $(6)$ \\
\hline Dependent Variable: & Log Loan & Default Rate & Log Loan & Default Rate & Log Loan & Default Rate \\
\hline In Network? & $\begin{array}{c}0.143^{* * *} \\
(0.042)\end{array}$ & $\begin{array}{c}-1.582^{* * *} \\
(0.353)\end{array}$ & $\begin{array}{c}0.184^{* * *} \\
(0.045)\end{array}$ & $\begin{array}{c}-1.414^{* * *} \\
(0.363)\end{array}$ & $\begin{array}{c}0.334^{* * *} \\
(0.057)\end{array}$ & $\begin{array}{c}-1.903^{* * *} \\
(0.512)\end{array}$ \\
\hline Fixed Effects & Expanded & Expanded & Expanded & Expanded & Expanded & Expanded \\
\hline $\mathrm{N}$ & 286,095 & 397,416 & 286,407 & 397,416 & 286,452 & 397,416 \\
\hline $\mathrm{R}^{2}$ & 0.60 & 0.86 & 0.60 & 0.86 & 0.60 & 0.86 \\
\hline
\end{tabular}




\section{Table V}

\section{Decomposing the Effect of Network Entry on External Borrowing}

This table decomposes the effect of network entry on bank credit. Column (1) considers the intensive margin and looks at average loan size from existing banks. Column (2) considers the extensive margin by examining whether network membership increases the number of lenders a firm is able to borrow from. Columns (3)-(4) test whether new credit is disproportionately coming from government or private banks. Column (5) tests how much of a firm's additional credit when it enters the network comes from new lenders that are its neighbor firm's lenders. "Expanded" fixed effects include firm and time fixed effects, as well as size decile, industry, and firm city location fixed effects, all interacted with time fixed effects. "In Network?" is a dummy variable equal to one when a firm is in the giant network and equal to zero when it is not. ${ }^{* * *}, * *, *$ indicate coefficients statistically distinct from 0 at the $1 \%, 5 \%$, and $10 \%$ levels, respectively. Robust standard errors are in brackets.

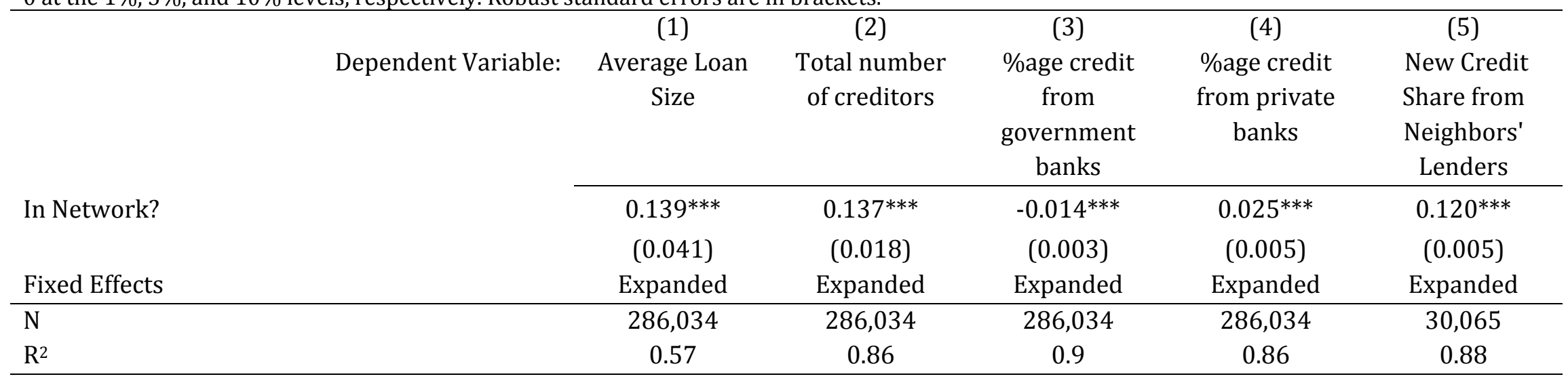




\section{Table VI}

\section{Heterogeneity in Network Benefit by Power of Connection - Borrowing}

This table examines heterogeneity in the network impact on a firm's borrowing. The dependent variable is log of firm borrowing. Each column examines how the network value differs depending on the (standardized) measure of a firm's power that is used (each measure is calculated when the firm is in and out of the giant network). Column (1) uses the number of neighbors to which a firm is directly connected. Column (2) uses the number of directors a firm's neighbors have. Column (3) looks at the total number of creditors to which a firm's neighbors have access. Column (4) is the firm's own Google PageRank. "Expanded" fixed effects include firm and time fixed effects, as well as size decile, industry, and firm city location fixed effects, all interacted with time fixed effects. "In Network?" is a dummy variable equal to one when a firm is in the giant network and equal to zero when it is not. ${ }^{* *}, * *, *$ indicate coefficients statistically distinct from 0 at the $1 \%, 5 \%$, and $10 \%$ levels, respectively. Robust standard errors are in brackets.

\begin{tabular}{|c|c|c|c|c|}
\hline & (1) & (2) & (3) & (4) \\
\hline In Network? (IN) & $\begin{array}{l}0.18^{* * *} \\
(0.043)\end{array}$ & $\begin{array}{c}0.179^{* * * *} \\
(0.043)\end{array}$ & $\begin{array}{c}0.174^{* * *} \\
(0.042)\end{array}$ & $\begin{array}{c}0.177^{* * *} \\
(0.042)\end{array}$ \\
\hline IN * \# Neighbors When In & $\begin{array}{l}0.099^{* *} \\
(0.040)\end{array}$ & & & \\
\hline IN * \# Neighbors When Out & $\begin{array}{l}-0.045 \\
(0.041)\end{array}$ & & & \\
\hline IN * \# Neighbors' Directors When In & & $\begin{array}{c}0.075^{* * *} \\
(0.027)\end{array}$ & & \\
\hline IN * \# Neighbors' Directors When Out & & $\begin{array}{l}-0.074^{*} \\
(0.043)\end{array}$ & & \\
\hline IN * \# Neighbors' Lenders When In & & & $\begin{array}{l}0.077^{* *} \\
(0.038)\end{array}$ & \\
\hline IN * \# Neighbors' Lenders When Out & & & $\begin{array}{c}-0.133^{* * *} \\
(0.043)\end{array}$ & \\
\hline IN * Google Rank When In & & & & $\begin{array}{c}0.167^{* * *} \\
(0.043)\end{array}$ \\
\hline IN * Google Rank When Out & & & & $\begin{array}{c}-0.138^{* * *} \\
(0.045)\end{array}$ \\
\hline Fixed Effects & Expanded & Expanded & Expanded & Expanded \\
\hline $\mathrm{N}$ & 286,034 & 286,034 & 286,034 & 286,034 \\
\hline $\mathrm{R}^{2}$ & 0.6 & 0.6 & 0.6 & 0.6 \\
\hline
\end{tabular}




\section{Table VII}

\section{Heterogeneity in Network Benefit by Power of Connection - Default}

This table examines heterogeneity in the network impact on a firm's borrowing. The dependent variable is default rate. Each column examines how the network value differs depending on the (standardized) measure of a firm's power that is used (each measure is calculated when the firm is in and out of the giant network). Column (1) uses the number of neighbors to which a firm is directly connected. Column (2) uses the number of directors a firm's neighbors have. Column (3) looks at the total number of creditors to which a firm's neighbors have access. Column (4) is the firm's own Google PageRank. "Expanded" fixed effects include firm and time fixed effects, as well as size decile, industry, and firm city location fixed effects, all interacted with time fixed effects. "In Network?" is a dummy variable equal to one when a firm is in the giant network and equal to zero when it is not. ${ }^{* *},{ }^{* *}, *$ indicate coefficients statistically distinct from 0 at the $1 \%, 5 \%$, and $10 \%$ levels, respectively. Robust standard errors are in brackets.

\begin{tabular}{|c|c|c|c|c|}
\hline In Network? (IN) & $\begin{array}{c}-1.605^{* * *} \\
(0.351)\end{array}$ & $\begin{array}{c}-1.578^{* * *} \\
(0.350)\end{array}$ & $\begin{array}{c}-1.588^{* * *} \\
(0.350)\end{array}$ & $\begin{array}{c}-1.577^{* * *} \\
(0.352)\end{array}$ \\
\hline IN * \# Neighbors When In & $\begin{array}{c}0.22 \\
(0.349)\end{array}$ & & & \\
\hline IN * \# Neighbors When Out & $\begin{array}{c}-1.028^{* * *} \\
(0.342)\end{array}$ & & & \\
\hline IN * \# Neighbors' Directors When In & & $\begin{array}{c}0.093 \\
(0.376)\end{array}$ & & \\
\hline IN * \# Neighbors' Directors When Out & & $\begin{array}{c}-1.384^{* * *} \\
(0.381)\end{array}$ & & \\
\hline IN * \# Neighbors' Lenders When In & & & $\begin{array}{c}0.554 * \\
(0.307)\end{array}$ & \\
\hline IN * \# Neighbors' Lenders When Out & & & $\begin{array}{c}-1.334^{* * *} \\
(0.381)\end{array}$ & \\
\hline IN * Google Rank When In & & & & $\begin{array}{c}-0.308 \\
(0.367)\end{array}$ \\
\hline IN * Google Rank When Out & & & & $\begin{array}{c}-0.808^{* *} \\
(0.383)\end{array}$ \\
\hline Fixed Effects & Expanded & Expanded & Expanded & Expanded \\
\hline $\mathrm{N}$ & 397,416 & 397,416 & 397,416 & 397,416 \\
\hline $\mathrm{R}^{2}$ & 0.86 & 0.86 & 0.86 & 0.86 \\
\hline
\end{tabular}




\section{Table VIII}

\section{Networks and Insurance}

This table examines insurance benefits provided by network membership. The dependent variable is the firm's own default rate. For each column, we examine how default rates co-vary with industry and city cohorts during common shocks. Columns (1)-(2) consider the full time-series data. Column (1) looks at the overall insurance effect for firms that are ever in the giant network. Column (2) separately estimates the insurance impact on the giant-network firms that enter/exit the network during our data period. Column (3) repeats Column (2) but restricts the sample to the periods for which we have directorship information. This is done in order to be able to compare the results to those of Column (4) in which we examine how network insurance varies for a firm when it is in the giant network compared to when that same firm is out. "Basic" fixed effects are firm and time fixed effects. "In Network?" is a dummy variable equal to one when a firm is in the giant network and equal to zero when it is not. Firm classifications "In-Out," "Always In," and "Other Networked" are as defined in Table I. ${ }^{* * *}, * *, *$ indicate coefficients statistically distinct from 0 at the $1 \%, 5 \%$, and $10 \%$ levels, respectively. Robust standard errors are in parentheses.

\begin{tabular}{|c|c|c|c|c|}
\hline City Default Rate & $\begin{array}{c}0.558^{* * *} \\
(0.006)\end{array}$ & $\begin{array}{c}0.545^{* * *} \\
(0.006)\end{array}$ & $\begin{array}{c}0.607^{* * *} \\
(0.006)\end{array}$ & $\begin{array}{c}0.607^{* * *} \\
(0.006)\end{array}$ \\
\hline ndustry Default Rate & $\begin{array}{c}0.633^{* * *} \\
(0.012)\end{array}$ & $\begin{array}{c}0.553^{* * *} \\
(0.012)\end{array}$ & $\begin{array}{c}0.514^{* * *} \\
(0.019)\end{array}$ & $\begin{array}{c}0.516^{* * *} \\
(0.019)\end{array}$ \\
\hline ty DR * Giant-Network Firm & $\begin{array}{c}-0.564^{* * *} \\
(0.020)\end{array}$ & & & \\
\hline dustry DR * Giant-Network Firm & $\begin{array}{c}-0.505^{* * *} \\
(0.021)\end{array}$ & & & \\
\hline City DR * In-out & & $\begin{array}{c}-0.424^{* * *} \\
(0.030)\end{array}$ & $\begin{array}{c}-0.348^{* * *} \\
(0.045)\end{array}$ & $\begin{array}{c}-0.311^{* * *} \\
(0.049)\end{array}$ \\
\hline Industry DR * In-out & & $\begin{array}{c}-0.394^{* * *} \\
(0.031)\end{array}$ & $\begin{array}{c}-0.051^{* * *} \\
(0.062)\end{array}$ & $\begin{array}{c}-0.075^{* * *} \\
(0.065)\end{array}$ \\
\hline Network? & & & & $\begin{array}{c}0.015 \\
(0.015)\end{array}$ \\
\hline Network? ${ }^{*}$ City DR * In-Out & & & & $\begin{array}{c}-0.139 * * * \\
(0.053)\end{array}$ \\
\hline Network? * Industry DR * In-Out & & & & $\begin{array}{c}-0.006 \\
(0.048)\end{array}$ \\
\hline Other Controls: Interactions of City & "Other & "Other & "Other & "Other \\
\hline DR and Industry DR with ... & Networked" & $\begin{array}{c}\text { Networked" } \\
\text { and "Always } \\
\text { In" }\end{array}$ & $\begin{array}{c}\text { Networked" } \\
\text { and "Always } \\
\text { In" }\end{array}$ & $\begin{array}{c}\text { Networked" } \\
\text { and "Always } \\
\text { In" }\end{array}$ \\
\hline Fixed Effects & Basic & Basic & Basic & Basic \\
\hline & $1,315,562$ & $1,315,562$ & 973,839 & 973,839 \\
\hline D & 0.76 & 0.76 & 0.83 & 0.83 \\
\hline
\end{tabular}




\section{Figure I}

\section{Giant Networks Around the World}

This figure displays network structure for a sample of public and/or large firms in (from top-left clockwise) the United States, United Kingdom, India, and Pakistan. Networks are formed by joining to firms together if they have at least one director in common. We include all public/large firms with available information on board of directors from three different sources $(12,543$ firms for U.S. from OneSource; 1,715 firms for U.K. from Boardex; 10,199 firms for India from OneSource; and 1,472 firms for Pakistan from the Pakistan Central bank data source). The spatial positioning of various networks is in order of network size starting with the giant network.

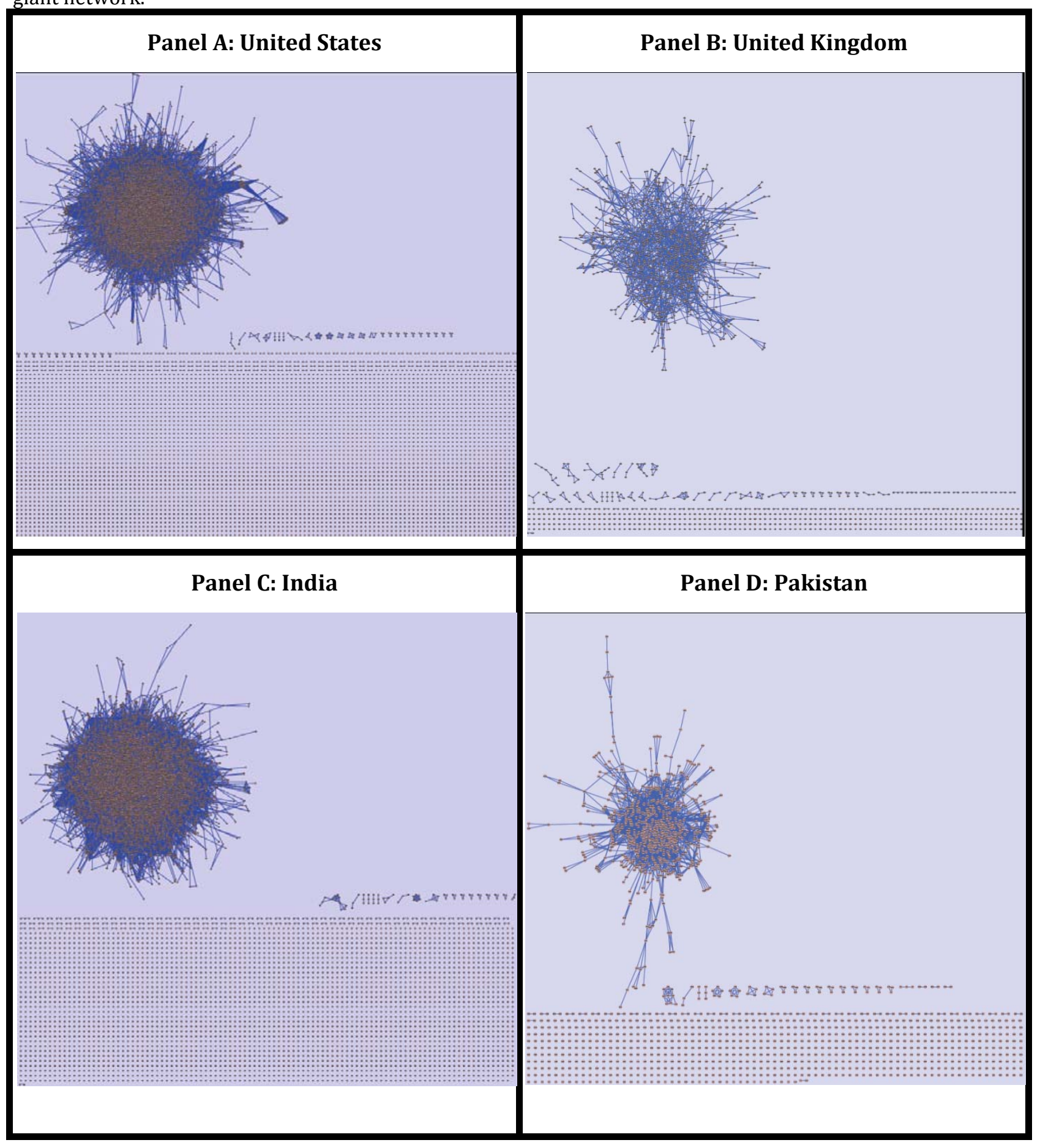




\section{Figure II}

\section{Network Construction}

This figure illustrates the hypothetical construction of a network. There are eight firms in the example (A through $\mathrm{H}$ ), and a total of fifteen directors sitting on the boards of these firms (labeled 1 through 15). Interlocked board linkages produce two distinct networks and two firms ( $\mathrm{G}$ and $\mathrm{H}$ ) that are not connected to anyone else. The largest network consists of Firms A through D, where Firms A, B, and C are linked to each other directly and Firm D is linked to Firms A and B indirectly through its direct link with Firm C. Thus, firms in the same network may be linked to each other through chains of indirect links.

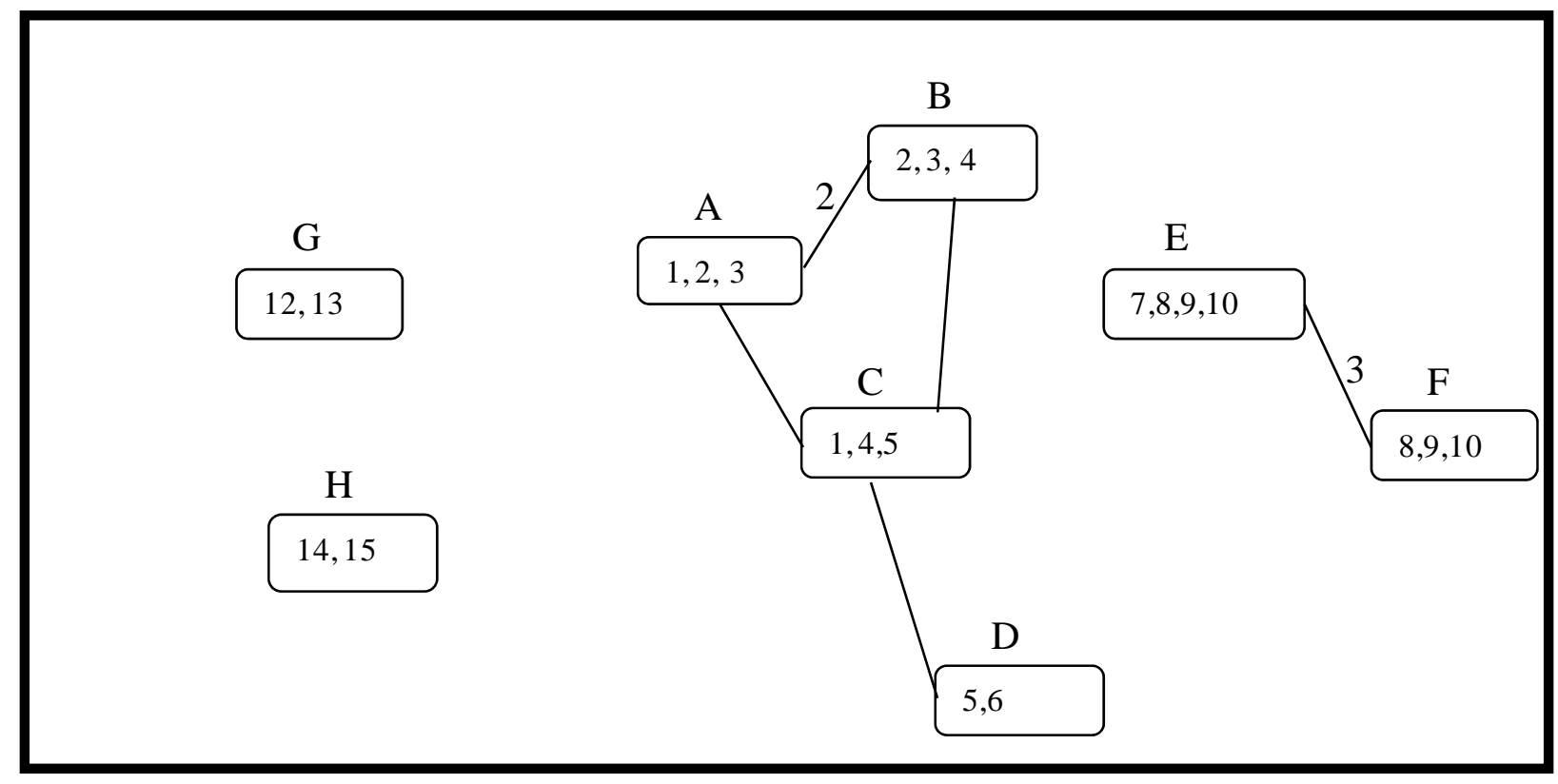




\section{Figure III}

\section{Giant-Network Structure}

The top panel displays the structure of the giant network. Firms that always remain inside the giant network are represented by black dots, while firms that enter and/or exit the giant network during our sample period are represented by red dots. Firm are linked if they share a common director. The bottom-left panel provides a zoom view near the "core" of the giant network. The bottom-right panel provides a zoom view of the peripheral area of the giant network, where firms have fewer connections to other firms than they do near the "core." Each node represents a firm, and the numbers inside indicate the number of firms that node is connected to.

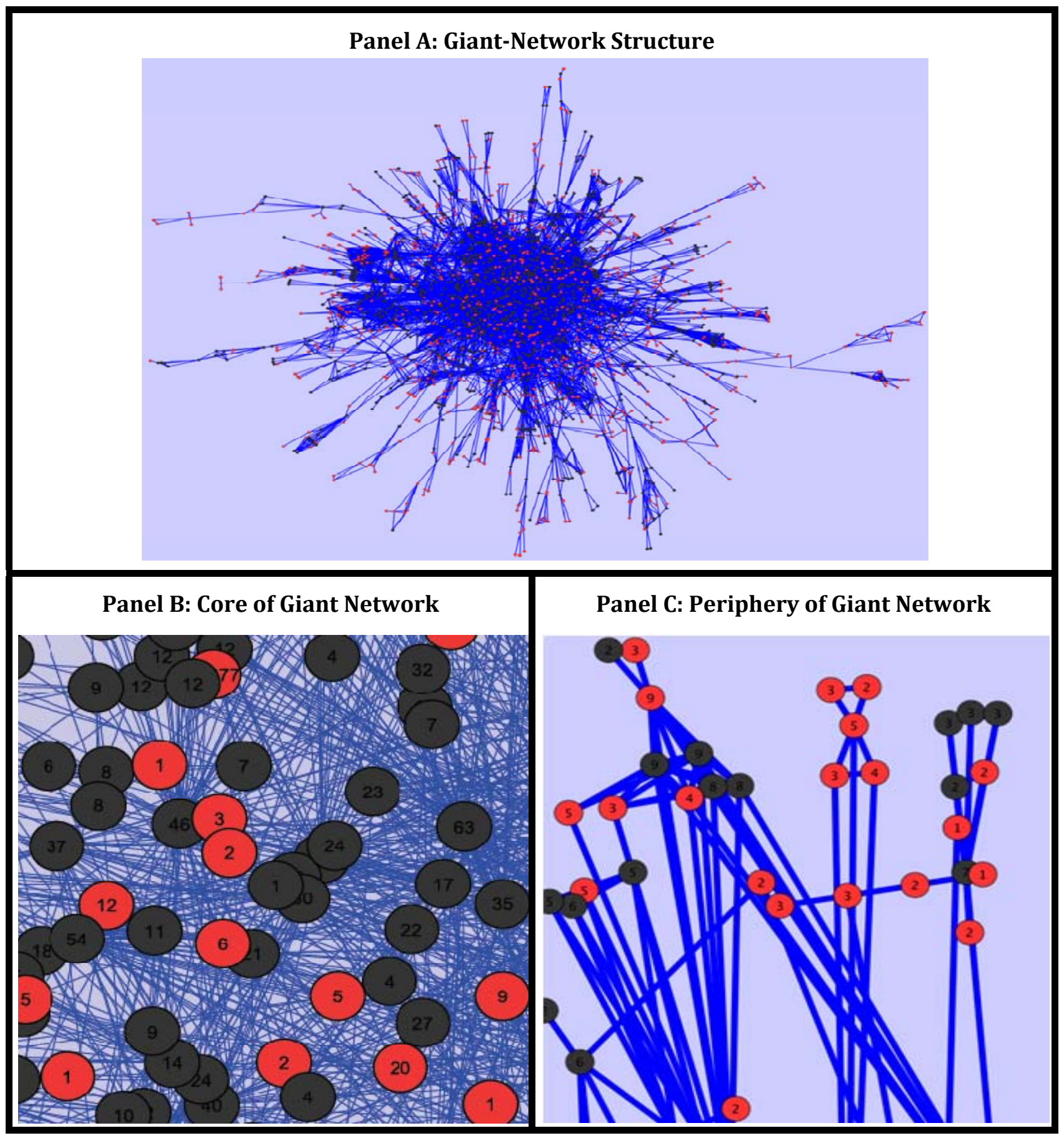




\section{Figure IV \\ Direct and Incidental Entrants}

This figure provides two real-world examples of entry into the giant network. The three firms in the left panel are connected to each other because they each have a director in common, but there is no director common to all three. The director who sits on the board of Firms 100 and 101 (colored white) enters the giant network. Firms 100 and 101 are thus defined as "direct entrants." In contrast, none of the directors of Firm 102 (colored yellow) changes its board membership. Firm 102 is thus classified as an "incidental entrant." The three firms in the right panel are connected in a triangle because there is a single director who is on the board of each of the three firms. However, a director who only sits on the board of Firm 106 enters the board of a giant-network firm. Thus, Firm 106 (colored white) becomes a "direct entrant," while Firms 104 and 105 (colored yellow) become "incidental entrants" into the giant network.

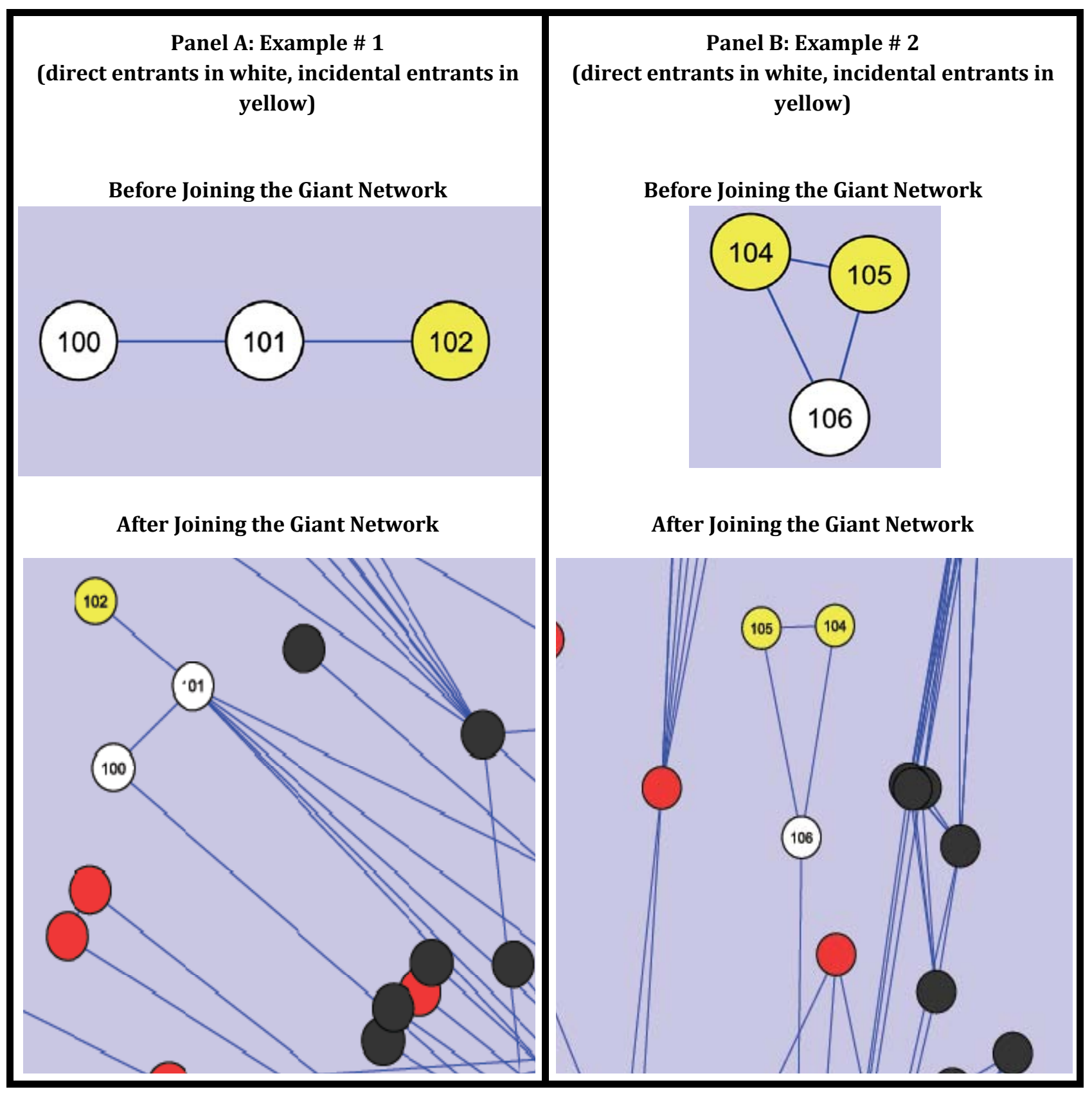


Figure V

\section{Sample Networked Firms Out of Giant Network}

The top panel displays network structures of firms that enter the giant network during our sample period when they are not in the giant network. We picked a few samples from different network sizes. The lower panel repeats the exercise but for firms that never enter the giant network during our sample period.

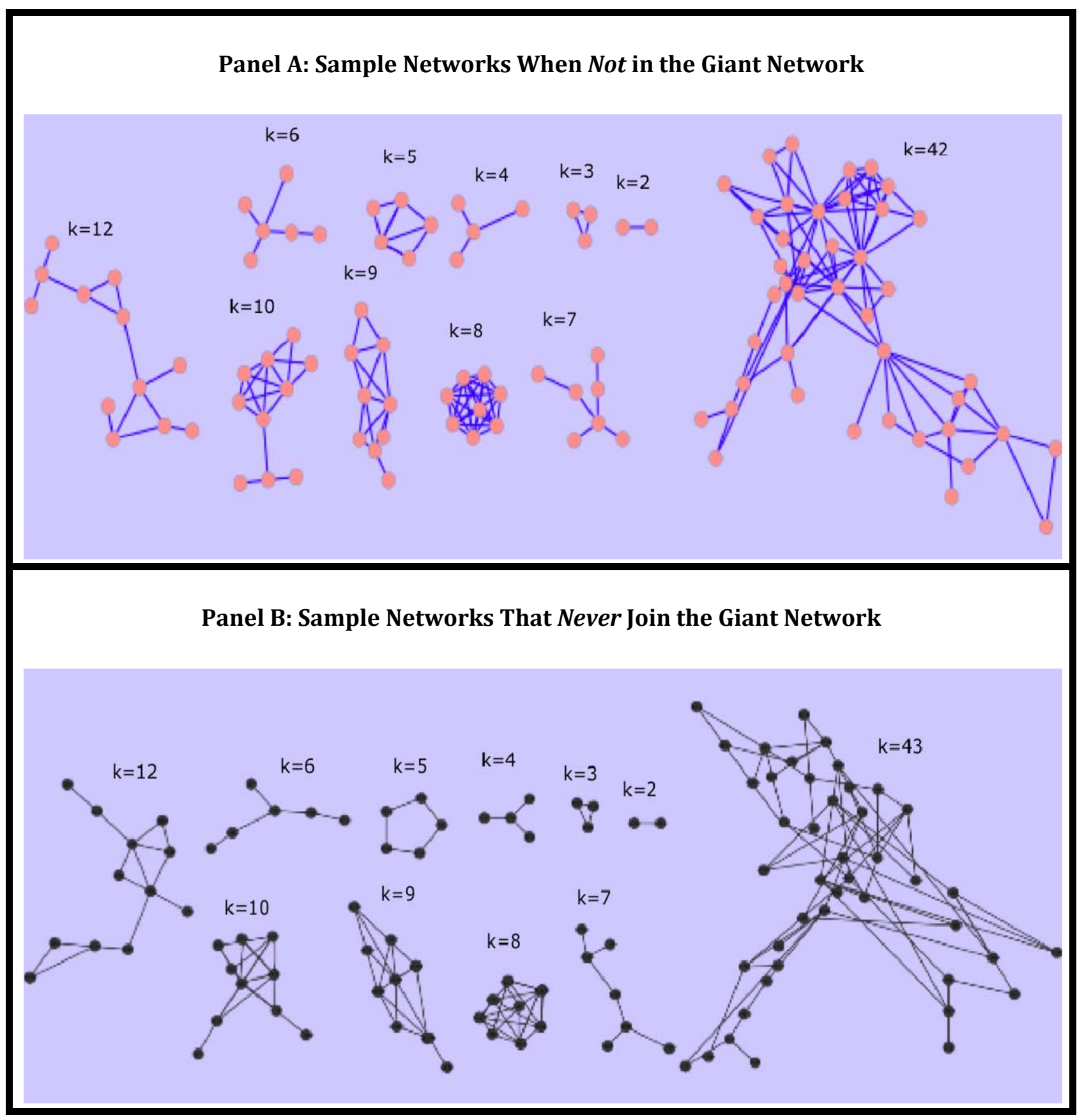




\section{Figure VI}

\section{Effect of Giant-Network Membership: Bank Credit and Financial Distress}

The top panel shows the log of total firm credit from the banking sector as a firm gains entry into the giant network. The bottom panel does the same for default rate. We follow a firm that enters or exits the giant network once during our sample period, and take out economy-wide aggregate shocks.
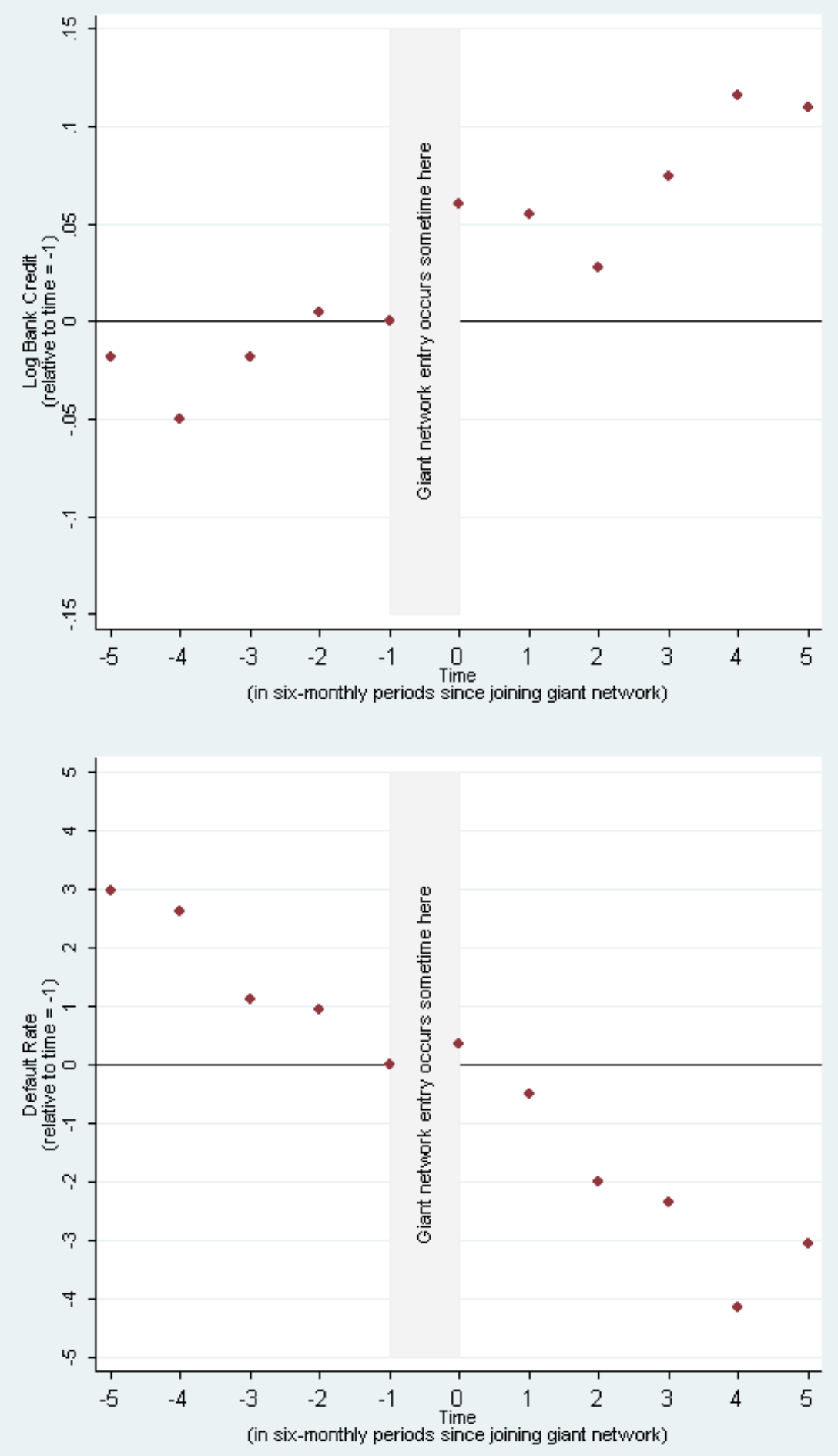


\section{Appendix Figure I \\ Network Structure in the Entire Economy}

Firms are linked if they share a common director. The spatial positioning of various networks is in order of network size starting with the giant network.

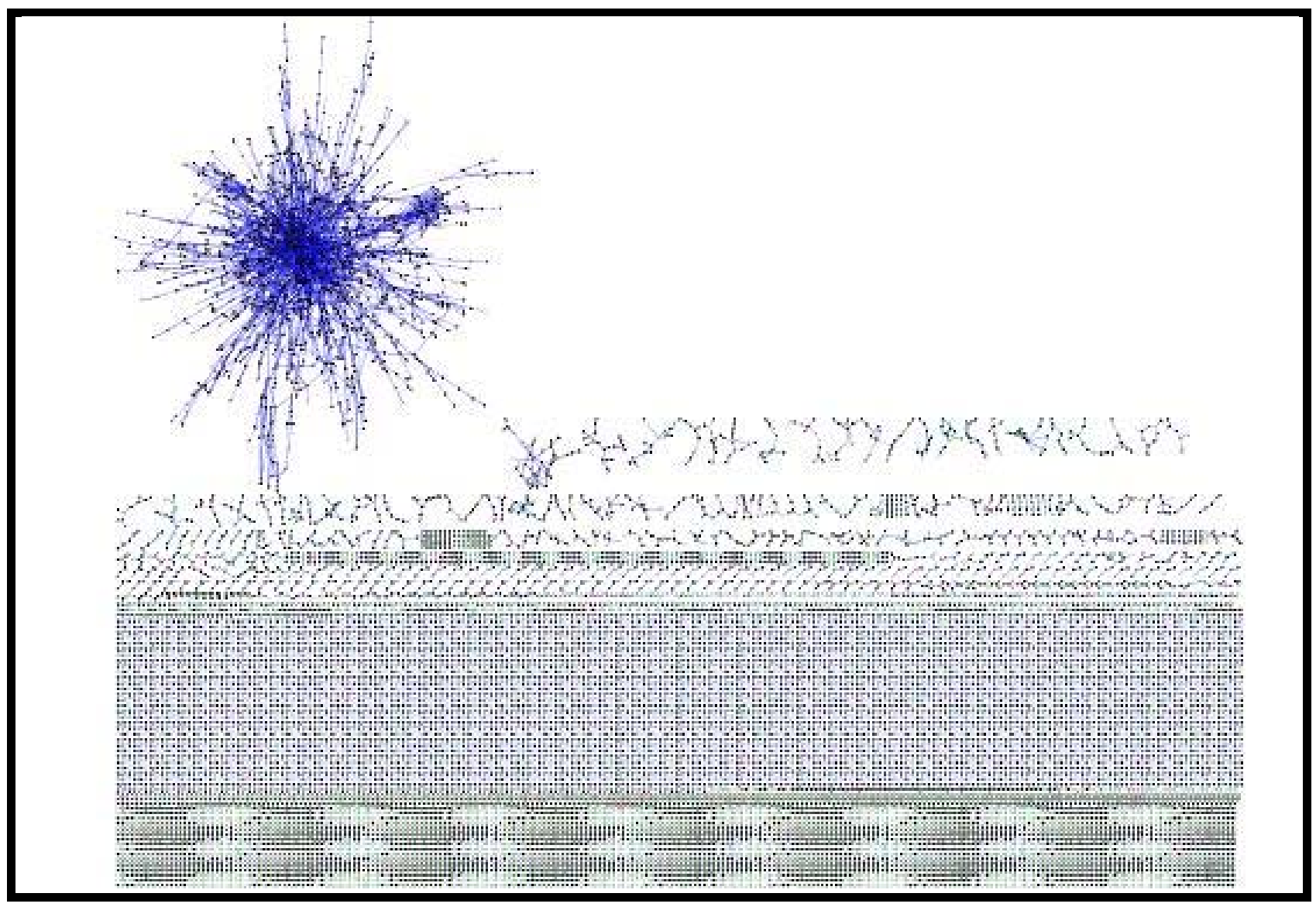




\section{Appendix Figure II}

\section{Giant-Network Structures Under Alternate Network Definitions}

This figure generates giant-network structure under alternative network definitions. The upper-left graph excludes government directors before constructing networks. The upper-right graph only includes links where the common director is also the equity holder in respective firms. The lower graph links two firms only if they have two or more directors in common.

\section{Panel A: Excluding Government Directors}

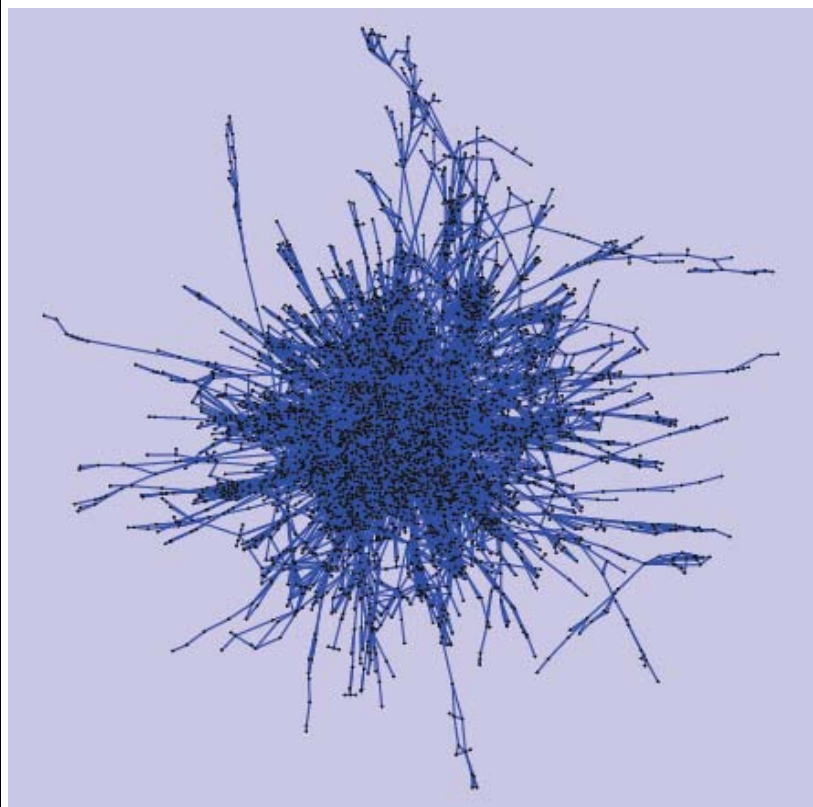

\section{Panel B: Common Directors With Equity}

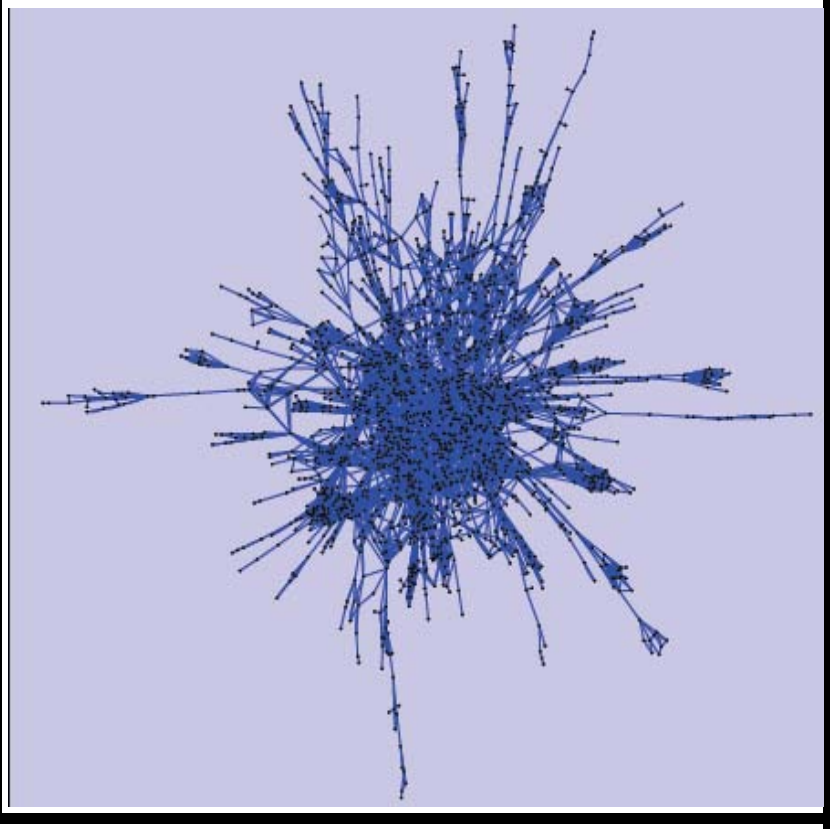

\section{Panel C: At Least Two Directors In Common}

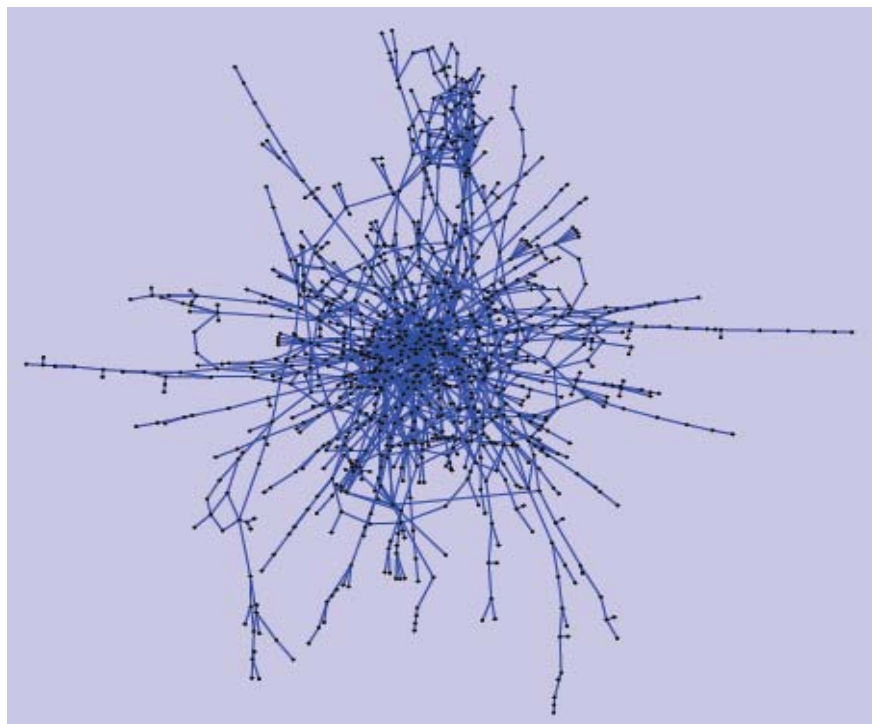




\section{Appendix Figure III}

\section{Neighbor Expansion from a Single Starting Node}

Panel A gives a starting node that has 6 immediate neighbors. Subsequent neighbors are indicated in yellow.

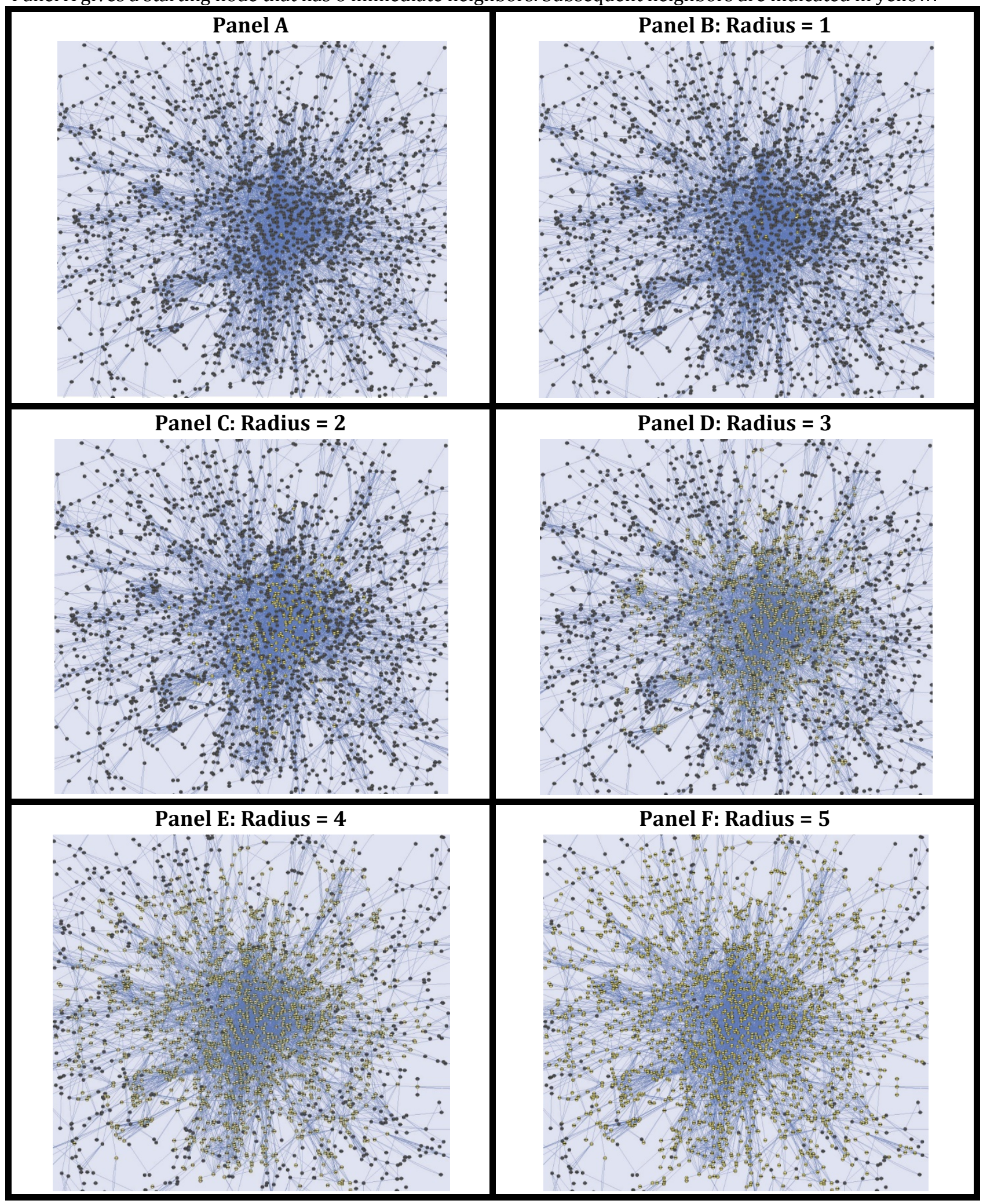

